\title{
Parameter Preservation at the Syntax-PF Interface: The $B a$ Construction Revisited
}

Chih-hsiang Shu

Institute of Linguistics, Academia Sinica

\begin{abstract}
In this paper, I argue for an analysis that treats the $b a$ construction in Chinese as a case of shape preservation-induced movement structure. Specifically, the robust preverbal adverbial and PP expressions and the mandatory $b a$-DP movement in ditransitive structures are both derived from a violable head directionality macroparameter under the Symmetrical Syntax Hypothesis, which allows directionality parameters to examine word order throughout the derivation. In addition to being able to capture the parallel syntactic properties of Scandinavian object shift, this account receives further empirical support from word order facts of Archaic Chinese and Bambara.
\end{abstract}

\section{Keywords}

ba construction, directionality parameters, Symmetrical Syntax Hypothesis, optional movement, syntax-PF interface

Studies in Chinese Linguistics, Volume 39, Number 1, 2018, 29-66 DOI: 10.2478/scl-2018-0002 (C2018 by T.T. $\mathrm{Ng}$ Chinese Language Research Centre, Institute of Chinese Studies, The Chinese University of Hong Kong 


\section{Introduction}

It has been noted in recent literature that syntactic movement may be triggered or conditioned by phonetic form (PF) linearization considerations. For example, in the OV language Turkish, the canonical position for reduced embedded clauses is preverbal, but complementizer-initial embedded clauses are obligatorily extraposed (Biberauer and Sheehan 2012). ${ }^{1}$

$$
\begin{array}{ll}
\text { a. Ben [siz-in Ankara-ya git-tiğ-iniz-i] } & \text { duy-du-m }(\mathrm{O} \mathrm{V}) \\
\text { I you-GEN Ankara-DAT go-NOM-poss.2pl-ACC } & \text { hear-pst-1sg } \\
\text { 'I heard that you went to Ankara.' } & \\
\text { (ÖZsoy 2001: 216) } &
\end{array}
$$
b. $\mathrm{t}_{\mathrm{i}}$ Anla-di-m
[ki onun bir derdi understand-PST-1SG that 3 SG.GEN one problem.POSs.3SG exists 'I realized that he had a problem.' (Haig 2001: 201)
c. ${ }^{*}[\mathbf{k i}$ onun bir derdi
var] anla-di-m
(O V/C IP)

The movement (1b) is generally understood as being triggered by the need for the sentence to harmonize the head-complement word order within the VP in the main clause and within the embedded CP. The resultant word order is consistently head $>$ complement ("A>B" here is to be read as "A precedes $\mathrm{B}$ ") in the sentence, so word order harmony is achieved.

Scandinavian object shift represents another case of interactions between PF linearization and movement. As is well known, the object shift is blocked if the lexical verb does not move:

a. Af hverju las látur pessa bók $_{\mathrm{i}}$ aldrei $\left[\mathrm{VP}_{\mathrm{v}} \mathrm{t}_{\mathrm{v}} \mathrm{t}_{\mathrm{i}}\right]$ ? $\left(\mathrm{VO}_{\text {Before move }} \mathrm{VO}_{\text {Affer move }}\right)$ why read Pétur this book never

b. *Af hverju hefur Pétur pessa bók $\mathrm{i}_{\mathrm{i}}$ aldrei leið $\mathrm{t}_{\mathrm{i}}$ ? $\left(\mathrm{VO}_{\text {Before move }} \mathrm{OV}_{\text {Affer move }}\right)$ why has Pétur this book never read

(Vikner 2006)

In recent generative works (e.g., Richards 2004, Richards 2007, and Richards 2008; Fox and Pesetsky 2005; Sheehan 2013), this phenomenon has generally been derived from a word order-preservation principle that applies throughout the derivation. Although the details of these analyses are different, they all agree that (2a) is grammatical because it preserves the $\mathrm{V}>\mathrm{O}$ word order throughout the derivation, whereas example (2b) is out because it deviates from this word order.

If these analyses are on the right track, we expect relevant theories to be extendable to other movement-related phenomena that interact with PF linearization. This prediction leads to the central fact to be investigated in this article: Mandarin

1 Similar facts are also found in Latin, German, and many other OV languages, according to Biberauer et al. (2014) and references cited there. 
$b a$-marked DP movement is obligatory whenever the verb is followed by additional material in the $v \mathrm{P}$ (or VP in a VP-shell analysis) (e.g., Chao 1968; Huang 1982; Li 1985, Li 1990; Tang 1990):

a. Ta [ba na-ben shu $\mathrm{i}_{\mathrm{i}}$ fang $\mathrm{t}_{\mathrm{i}}$ zai zhuoshang. $(\text { ba } \mathrm{O}>\mathrm{V}>\mathrm{PP})^{2}$ he BA that-CL book put at table.top

'He put that book on the table.'

b. *Ta fang na-ben shu zai zhuoshang. $\quad(* \mathrm{~V}>\mathrm{O}>\mathrm{PP})$ he put that-CL book at table.top

From a macroparametric point of view, the requirement is similar to the constraint on Scandinavian object shift under Richards's (2004, 2007, 2008) analysis, in that the resultant shapes of both types of movement are sensitive to the head directionality parameter settings of the languages. Icelandic OS in (2) requires a resultant $\mathrm{V}>\mathrm{O}$ order, and Icelandic is a head-initial language. Mandarin $b a$ construction produces $\mathrm{O}>\mathrm{V}$ order, and Mandarin is to some extent a head-final language, since VP-adverbs are generally preverbal (Huang 1982). If the similarity between these connections is real, we have additional evidence for theories that allow PF linearization to interact with movement, as well as additional evidence for the need for a PF-based analysis of the $b a$ construction first suggested by Huang (1982).

In this article, I present an analysis of $b a$-marked DP movement in Mandarin Chinese that allows the movement to be conditioned by PF-linearization parameters and established principles. According to this view, $b a$-marked DP movement in (3a) is optionally triggered by a subtype of accusative Case assignment, and this movement is mandatorily evaluated and licensed by the HDP setting (head-final) of Mandarin that applies throughout the derivation, which allows constituents to violate the head-final word order requirement only once if the violation is imposed by more specific directionality parameter settings. The lack of movement in (3b) is ruled out by the same mandatory parameter-setting evaluation mechanism, since the head-final word order requirement is illicitly violated twice.

$$
\begin{aligned}
& \text { a. Ta } \left.\left[_{\text {VoiceP }}[b a \text { na-ben shu }]_{\mathrm{i}}\left[\left[_{\text {Voice' }^{\prime}} \text { Voice }^{0} \quad{ }_{\nu \mathrm{P}} \text { fang t. } \text { [PP }_{\mathrm{PP}} \text { zai zhuoshang }\right]\right]\right]\right] \\
& \left(\left[\left[_{\text {VoiceP }} \mathrm{V}>\mathrm{PP}\right] \text {; HDP setting observed }\right)\right. \\
& \text { b. *Ta }\left[_ { V o i c e P } \left[{ }_{v \mathrm{P}} \text { fang } \quad[\text { nP } \text { na-ben shu }]\left[_{\mathrm{PP}} \text { zai zhuoshang] }\right]\right.\right. \\
& \left(\left[{ }_{\text {VoiceP }} \mathrm{V}>\mathrm{DP}>\mathrm{PP}\right] ; \text { HDP setting violated }\right)
\end{aligned}
$$

This account has the following advantages. Descriptively, it has substantial empirical coverage: the Chinese and the Scandinavian word order facts are accounted for by

2 The abbreviations of the gloss are as follows: BA: marker of the BA construction; BEI: passive marker; CL: classifier; DE: modification marker or postverbal manner/resultative marker; DOU: focus marker; DUR: durative aspect; EXP: experiential aspect; PFV: perfective aspect; POSS: possessive marker; PRT: particle; SFP: sentence-final particle; YІ: marker of the YI construction. 
similar interactions between PF parameters and syntactic movement. Theoretically, it is simpler and more constrained than the X-bar-theoretical PF-based account (Huang 1982); in addition, it offers additional support for the Symmetrical Syntax Hypothesis (SSH) (e.g., Chomsky 1995; Richards 2004).

The remainder of the paper is organized as follows. In Section 2, I present empirical facts showing that the HDP in Mandarin is active across derivational stages, not just at the stage when a Merge operation is implemented. This descriptive generalization can capture the fact that the verb generally cannot be followed by two or more constituents in the $v \mathrm{P}$, and the fact that Mandarin utilizes the $b a$ construction as a repair strategy. In Section 3, I argue that these facts can be naturally accounted for under the $\mathrm{SSH}$, which allows linear order to be determined at the syntax-PF interface. In Section 4, I extend this analysis to Archaic Chinese (AC) and Bambara. I compare the proposed analysis with alternative approaches in Section 5. Section 6 concludes the paper.

\section{Linearization consistency in Mandarin Chinese}

In this section, I show that there is a connection between narrow syntax computations and PF linearization requirements of the following kind in Mandarin Chinese:

\section{(5) Linearization Consistency (LinCon)}

Within the lexical projection of $v \mathrm{P}$, if a HDP setting is $v_{\alpha}$ for derivational stage $n_{i}$, the setting is also $v_{\alpha}$ for derivational stage $n_{j}, i \neq j$.

This informal principle is similar to Huang's (1982) proposal about directionality parameters of Mandarin, according to which the X-bar structures at PF must be of a certain configuration, which also regulates the landing sites of movements. However, being stated in more general terms, (5) differs from Huang's (1982) proposal in that the former does not assume X-bar structures. In what follows, I provide evidence for this empirical claim.

\subsection{A prohibition against two postverbal elements in the $v \mathrm{P}$}

It is well known that there is a general constraint that prohibits more than one postverbal element in Mandarin (e.g., Chao 1968; Huang 1982; Koopman 1984; Travis 1984; Li 1985, Li 1990; Tang 1990; Sybesma 1992). This constraint involves a set of facts that can be accommodated by LinCon, without which additional conditions are required.

Under classic theoretical assumptions that allow directionality parameters, the constraint can be more precisely stated as two parametric settings and one condition:

(6) Theta-directionality parametric (TDP) settings in Mandarin

Object DPs, complements (resultative and goal phrases), and certain cases of durative, frequency, and manner (DFM) expressions follow the lexical verb ( $\mathrm{V}>\mathrm{XP} ; \mathrm{XP}=$ complements or certain DFM expressions). 
(7) The HDP setting in Mandarin (first approximation)

All $v \mathrm{P}-$ level expressions not covered by TDP settings, including the landing sites of movements, precede the lexical verb $\left(\mathrm{YP}>\mathrm{V} / \mathrm{YP}_{\mathrm{i}}>\mathrm{V}>\mathrm{t}_{\mathrm{i}} ; \mathrm{YP}=v \mathrm{P}\right.$ internal expressions not covered by TDPs).

(8) Postverbal Linearization Condition (PLC) (commonly known as the Postverbal Structural Constraint $[\mathrm{PSC}]^{3}$ )

A lexical verb cannot be overtly followed by more than one expression covered by TDP settings $(* \mathrm{~V}>\mathrm{DP}>\mathrm{XP}$; all expressions are overt).

The TDP settings in (6), which have been proposed by Travis (1984), Mulder and Sybesma (1992), and Ernst (2002), ${ }^{4}$ among others, concern the following illustrated facts:
a. Lisi xihuan
Zhangsan.
$\left(\mathrm{V}>\mathrm{DP}_{\mathrm{obj}}\right)$
Lisi like Zhangsan.
'Lisi likes Zhangsan.'
b. *Lisi Zhangsan xihuan. $\quad\left(* \mathrm{DP}_{\text {obj }}>\mathrm{V}\right)$
Lisi Zhangsan like

(10) a. Lisi pao de \{hen lei/ hen kuai\}. ( $\left(\mathrm{V}>\mathrm{Adv}_{\text {resultative }} / \mathrm{Adv}_{\text {manner }}\right)$

Lisi run DE very tired/ very fast

'Lisi ran himself tired/Lisi ran vary fast.'
b. *Lisi hen lei
(de) pao.
$\left(* \mathrm{Adv}_{\text {resultative }}>\mathrm{V}\right)$
Lisi very tired DE run
c. Lisi hen kuai de pao.
Lisi very fast DE run
'Lisi ran very fast.'
$\left(\mathrm{Adv}_{\text {manner }}>\mathrm{V}\right)$

(11)
a. Lisi pao dao Taibei le.
Lisi run to Taipei SFP

$$
\left(\mathrm{V}>\mathrm{PP}_{\text {goal }}\right)
$$
'Lisi ran to Taipei.'

b. *Lisi dao Taibei pao le. ${ }^{5}$

Lisi to Taipei run SFP

'Intended: Lisi ran to Taipei.'

(12) a. Lisi pao le \{yi-ge xiaoshi/san ci\}. $\quad\left(\mathrm{V}>\mathrm{DP}_{\text {durative }} / \mathrm{DP}_{\text {frequency }}\right)$ Lisi run PFV one-CL hour/ three time 'Lisi ran for one hour/Lisi ran three times.'
b. *Lisi \{yi-ge xiaoshi/san ci\} pao le.

Lisi one-CL hour/ three time run PFV

3 See Huang (1994, 2015, among others). In earlier works (Huang 1982, Huang 1984, among others), this condition is called the X-bar filter and the Phrase Structure Condition, respectively.

4 For Ernst (2002), this is a parametric setting within lexical projections.

5 This sentence is well formed as a serial verb construction, with the meaning 'Lisi went to Taipei to run.' 
The examples show that, except for manner expressions, all expressions regulated by TDPs have to follow the verb.

The HDP setting in (7), which is based on the proposal by Huang (1982), Li (1985, 1990), and Ernst (2002: 166ff.), and various other works, is illustrated as follows:

a. Ta (zenme) chi mian (*zenme)? (AdvP $\left.\mathrm{P}_{\text {instrument }} / \mathrm{AdvP}_{\text {manner }}>\mathrm{V}\right)$ he how eat noodle 'How does he eat noodles?'

b. Lisi (changchang) chi mian (*changchang). $\quad\left(\operatorname{AdvP}_{\text {frequency }}>V\right)^{6}$ Lisi often eat noodle 'Lisi eats noodles often.'

c. Ta (xiao-zhe) jin fangjian (*xiao-zhe). $\quad\left(\mathrm{VP}_{\text {depictive }}>\mathrm{V}\right)$ he laugh-DuR enter room 'He entered the room laughing.'

d. Lisi (cong taibei) lai (*cong taibei). $\quad\left(\mathrm{PP}_{\text {source }}>\mathrm{V}\right)$ Lisi from Taipei come 'Lisi came from Taipei.'

e. Lisi (ba na-ben shu $\mathrm{i}_{\mathrm{i}}$ )fang $\mathrm{t}_{\mathrm{i}}$ zai zhuoshang $\left({ }^{*}\right.$ ba na-ben $\left.\mathrm{shu}_{\mathrm{i}}\right)$. $\left(\text { ba DP} \mathrm{i}_{\mathrm{i}}>\mathrm{V}>\mathrm{t}_{\mathrm{i}}\right)^{7}$ Lisi BA that-CL bookput at table.top ba that-CL book 'Lisi put that book on the table.'

These examples show that Mandarin to some extent behaves like typical headfinal languages, despite its being classified as an SVO language.

Next, the PLC in (8), based on Huang's (1982) PSC, is illustrated by the following examples: ${ }^{8}$
a. *Ta fang na-ben shu zai zhuoshang.

$$
\left(* \mathrm{~V}>\mathrm{DP}_{\text {obj }}>\mathrm{PP}_{\text {goal }}\right)
$$ he put that-cL book at table.top

b. Ta $\left[\begin{array}{ll}\mathrm{ba} & \text { na-ben } \mathrm{shu}_{\mathrm{i}}\end{array}\right.$ fang $\mathrm{t}_{\mathrm{i}}$ zai zhuoshang $\left(b a \mathrm{DP}_{\mathrm{i}}>\mathrm{V}>\mathrm{t}_{\mathrm{i}}>\mathrm{PP}_{\text {goal }}\right)$ he BA that-CL book put at table.top

'He put that book on the table.'
a. $*$ Ta ca de na-zhang zhuozi hen ganjing. $\left(* \mathrm{~V}>\mathrm{DP}_{\text {obj }}>\mathrm{Adv}_{\text {resultative }}\right)$ he wipe DE that-CL table very clean

\footnotetext{
6 As has been illustrated in (12), frequency adjuncts occur postverbally when they are in the [numeral-measure word] form. I have no comment on this other than that they follow different directionality settings.

7 For motivations for a movement-based analysis of the $b a$ construction, see Sybesma (1999), Li (2006), Huang et al. (2009), and Paul (2015), among others.

8 There are several other cases associated with PLC effects, which will not be discussed here, including, among others, retained object or pseudoobject constructions (Huang 1982; Paul 2015), certain ditransitive constructions discussed by Huang (1982), and trisyllabic resultative compound constructions (Feng 2000).
} 
b. Ta [ba na-zhang zhuozi $\mathrm{i}_{\mathrm{i}}$ ca de $\mathrm{t}_{\mathrm{i}}$ hen ganjing. ( $b a \mathrm{DP}_{\mathrm{i}}>\mathrm{V}>\mathrm{t}_{\mathrm{i}}>\mathrm{PP}_{\text {resultative }}$ ) he BA that-CL table wipe DE very clean

'He wiped that table very clean.'

(16) a. *Tama-le ren $\left\{\right.$ san ci/ yi-ge xiaoshi\}. $\left(* \mathrm{~V}>\mathrm{DP}_{\text {obj }}>\mathrm{DP}_{\text {frequency }} / \mathrm{DP}_{\text {durative }}\right)$ he scold-PFvpeople three time/one-CL hour

b. Ta ma ren ma-le $\mathrm{t}_{\mathrm{i}}\left\{\right.$ san ci/ yi-ge xiaoshi\}. $\left(\mathrm{V}>\mathrm{DP}_{\text {obj }}>\mathrm{V}>\mathrm{DP}_{\text {freq. }} / \mathrm{DP}_{\text {dur. }}\right)$ he scold people scold-PFV three time/ one-CL hour

(17) a. *Ta ma de Zhangsan hen dasheng. (*V $>\mathrm{DP}_{\text {obj }}>\mathrm{Adv}_{\text {manner }}$ ) he scold DE Zhangsan very loud

b. Ta ma Zhangsan ma de hen dasheng. (V $>\mathrm{DP}_{\mathrm{obj}}>\mathrm{V}>\mathrm{Adv}_{\text {manner }}$ ) he scold Zhangsan scold DE very loud

'He scolded Zhangsan very loudly.'

c. Zhangsan ${ }_{i}$, ta ma $t_{i}$ de hen dasheng. $\left(\mathrm{DP}_{(\mathrm{obj}) \mathrm{i}}>\mathrm{V}>\mathrm{t}_{\mathrm{i}}>\mathrm{Adv}_{\text {manner }}\right)$ Zhangsan he scold DE very loud

'Zhangsan, he scolded very loudly.'

Although there are disagreements about analyses of these examples ${ }^{9}$ and some of them have even been argued not to be instances of PLC effects since 1990s (e.g., Huang 1994; Huang et al. 2009), there are still reasons to continue acknowledging the existence of PLC effects. First of all, Mulder and Sybesma (1992) and Sybesma (1999) note that indefinite DPs can stay in situ with goal phrases, and these authors attribute the contrast in (14) to a definiteness effect.

(18) Ta fang yi-ben shu zai zhuoshang. $\quad\left(\mathrm{V}>\mathrm{DP}_{\text {obj(indef) }}>\mathrm{PP}_{\text {goal }}\right)$ he put one-CL book at table.top

'He put a book on the table.'

However, this still does not explain why postverbal definite DP objects are allowed in non-PLC configurations (cf. 9a). This suggests that PLC is in effect in (14). Second, according to Huang (1982: 375, 1994), Sybesma (1999), Huang (2006a), Cheng (2007), and Huang et al. (2009), among others, resultatives in Mandarin do not exhibit PLC effects, since, according to their judgments, sentences similar to (15a) are fine, and Mandarin resultatives may involve a verb taking a single clausal complement in the base-merged position, since unergative verbs like $k u$ 'cry' are fine in resultatives. However, according to the judgments of my informants and me, there is a clear contrast between (15a) and (15b), and they involve typical transitive resultative constructions. This is congruent with google search results of “ca de zhuozi hen 擦得桌子很” and “ba zhuozi ca de hen 把桌子擦得很”, which

9 Huang (1994), for instance, generally denies the status of PLC (his PSC) as an adequate descriptive generalization, in contrast to his earlier works (Huang 1982, Huang 1984) and certain recent works on Chinese syntax (Li 2006; Paul 2015; among others). In addition, although Huang (1994) and Huang et al. (2009) adopt a VP-shell-based analysis of postverbal adverbials, Ernst (2002) adopts an adjunct-based analysis. 
show robust instances of (15b)-type sentences and only two instances of (15a)type sentences, one of which involves baby talk. Third, the contrast in (16) is generally uncontroversial, but its relevance to PLC is obscured by the fact that $\mathrm{V}>\mathrm{DP}_{\text {obj }}>\mathrm{DP}_{\text {frequency }} / \mathrm{DP}_{\text {durative }}$ word order becomes fine when the object DP is definite (e.g., Huang 1994; Huang et al. 2009).

$$
\begin{aligned}
& \text { Ta da-guo neixie huaidan liang ci. } \quad\left(\mathrm{V}>\mathrm{DP}_{\text {obj(def) }}>\mathrm{Adv}_{\text {durative }}\right) \\
& \text { he beat-EXP those bad.guy two time } \\
& \text { 'He beat those bad guys twice.' }
\end{aligned}
$$

Nevertheless, the acceptability of a postverbal definite DP in this construction could be due to the availability of an alternative structure for frequency and durative constructions, according to which liang $c i$ is predicate of the sentence, and the whole clause preceding liang $c i$ is the clausal subject (Teng 1975; Huang 1982: 97; Li 1987; Huang et al. 2009). ${ }^{10}$ If this analysis is on the right track, it is still plausible to regard the contrast in (16) as a PLC effect, with the assumption that indefinite DPs cannot occur in the clausal subject in the subject $_{\text {clause }}-$ predicate $\left._{\text {durative }}\right]$ structure due to some yet-unknown reason. ${ }^{11}$ Fourth, Huang et al. (2009) attributes the ill-formedness of examples like (17a) to the morphosyntactic requirements of the morpheme de instead of to PLC. However, this may also mean that (17a) is illicit because of the PLC violation and the violation of the requirements for $d e$. All the facts in (14)-(17) taken together clearly show that there is a requirement on the overt linear order of postverbal elements inside the Mandarin $v \mathrm{P}$.

With these basic observations established, we are now in a position to show that PLC, as stated in $(20)(=(8))$, can be subsumed under condition $(21)(=(5))$, if we slightly modify the HDP setting in Mandarin in (7) as (22):

(20) The PLC

A lexical verb cannot be overtly followed by more than one expression covered by TDP settings $(* \mathrm{~V}>\mathrm{DP}>\mathrm{XP}$; all expressions are overt).

(21) LinCon

Within the lexical projection of $v \mathrm{P}$, if a HDP setting is $v_{i}$ for derivational stage $n_{i}$, the setting is also $v_{i}$ for derivational stage $n_{j}, i \neq j$.

10 Although Huang et al. (2009: 94) at first consider this as a possible scenario, they later reject it due to the different semantic requirements between double object constructions and transitive constructions with clause-final durative phrases. This does not seem to be a knock-down argument, as they do not have an explanation of this contrast, and their double-object construction example does not contain a definite DP direct object.

11 Huang et al.'s (2009: 95) analysis for structures in (16) attributes the contrast to a constraint that requires nonreferential constituents to be base-merged with the verb to form the smallest possible constituent, under Larson's (1988) VP-shell analysis of adverbials. This analysis, however, faces two empirical challenges. First, it has trouble accounting for (18), where a nonreferential DP precedes the goal PP. Second, it is not applicable in English, since John scolded people twice is fine. 
The HDP setting in Mandarin (second version)

All $v$ P-level expressions not covered by TDP settings, including the landing sites of movements, precede the lexical verb $\left(\mathrm{YP}>\mathrm{V} / \mathrm{YP}_{\mathrm{i}}>\mathrm{V}>\mathrm{t}_{\mathrm{i}} ; \mathrm{YP}=v \mathrm{P}\right.$ internal expressions not covered by TDPs). The setting can be violated once and no more than once $(* \mathrm{~V}>\mathrm{DP}>\mathrm{XP})$ if repair strategies are available.

In the second version of the HDP setting in Mandarin, it is specified to allow one and only one violation when repair strategies are available. Putting aside the theoretical consequences of this modification until the next section, this move allows us to subsume PLC under LinCon. Consider first the derivation stage of (14b) when the VP-shell structure is being formed and the $b a$ DP has not moved:

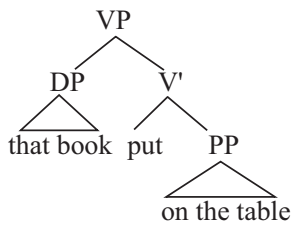

At this stage, the HDP setting is active, but it is not yet detectable, since the verb fang 'put' can only move leftward, as per the TDPs. Now, consider the next stage, when the resultant structure undergoes further merger:

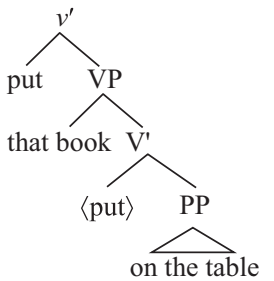

At this stage, the HDP setting is also active, and it is detectable; since the direct object is able to move to a preverbal position, it serves as a repair strategy for the HDP setting. In this movement configuration, the HDP setting is only violated once, which still makes the configuration licit for the PF linearization. On the other hand, if movement does not occur, and the $v^{\prime}$ or $v \mathrm{P}$ continues to merge with the external argument and $v \mathrm{P}$-external elements, the HDP setting is illicitly violated, since repair strategies are available, yet the setting is violated twice.

Without LinCon, the contrasts in (14)-(17) cannot be derived by the HDP setting alone. In this scenario, at derivation stage (24), the HDP setting, which cannot see the earlier derivations, only sees the ordering relations between the raised verb and the VP complement. The ordering relations between the verb and the PP on the table are no longer visible. No HDP violations are incurred if the object DP does not move, and therefore all the (a) examples should be well-formed, contrary to fact. The only way to account for the contrasts would be to resort to PLC, which by itself does not follow from any theoretical principles. 


\subsection{The $b a$ construction as an optional movement structure ${ }^{12}$}

Another set of facts in Mandarin that can be accommodated by LinCon and cannot be derived from traditional views of HDPs alone involves the existence of optional operations that are constrained by economy principles regarding linearization.

The existence of optional operations in Mandarin is a corollary of the PLC effects, since sentences with potential violations of PLC effects (e.g., (14)-(17)) need to be expressed somehow. These operations have been extensively discussed by Huang (1984), which include the $b a$ construction, verb copying, incremental theme construction (see also Huang et al. 2009: 98), verb-resultative compound lexicalization/reanalysis process (see also Huang 1992), among others. ${ }^{13}$ Now let us look at the optionality of the $b a$ DP movement in more detail.

The canonical ${ }^{14} b a$ construction, illustrated in $(25)(=(3 a))$, is generally regarded as a movement structure (e.g. Sybesma 1999; Li 2006; Huang et al. 2009; Paul 2015), where the $b a$-marked DP is moved from the postverbal position, the canonical position for direct objects, to the preverbal position. ${ }^{15}$

(25) Ta [ba na-ben $\mathrm{shu}_{\mathrm{i}}$ ] fang $\mathrm{t}_{\mathrm{i}}$ zai zhuoshang.

he BA that-CL book put at table.top

'He put that book on the table.'

Modern generative analyses generally left unspecified what triggers the movement, but there is clear evidence that the landing site with $b a$-marking is a position that Case is assigned, but no new theta-role is assigned. First of all, when $b a$ is present, it is not possible for the direct object to stay in the postverbal position. Note that (26) is not ruled out by PLC, since indefinite DPs are generally not subject to this condition.

12 I limit my discussion to the canonical $b a$ construction. Causative $b a$ constructions have different properties (Sybesma 1999; Huang et al. 2009).

13 These facts are not unanimously regarded as repair strategies for PLC violations. Huang (1992) treats $b a$-marked resultative constructions with unergative verbs like $k u$ 'cry' (e.g., Ta ba Lisi ku de hen shangxin. 'His crying made Lisi very sad.') and their ba-less counterparts (e.g., Ta ku de Lisi hen shangxin.) as free variations, where the latter violates PLC. In Huang (1994), incremental theme constructions (e.g., Wo mai-guo yi-nian de yu. 'I sold fish for a year.') are treated as verb raising constructions with two postverbal elements, which violates PLC. However, these analyses remain controversial, as Huang et al. (2009) again treats $b a$ constructions as movement structures and again acknowledges the possibility of the analysis treating incremental themes as DP constituents (with no PLC violation). Since the general effects of PLC in Mandarin are undeniable, it seems more plausible to maintain Huang's (1984) original view about these constructions as repair strategies. I leave the details of these specific constructions for future research.

14 The causative $b a$ construction (Huang et al. 2009) has different properties and will not be discussed here.

15 Huang (1992) and Lin (2001) adopt a nonmovement analysis for the $b a$ construction. This analysis is challenged by the adverbial placement facts noted by Huang et al.'s (2009: 176), as well as other facts such as the specificity restriction (Li 2006). 
*Ta ba fang-le yi-ben shu zai zhuoshang. he BA put-PFV one-CL book at table.top

Second, $b a$ can only be followed by a DP, and it has to be adjacent to this DP. These facts, along with the assumption that movement is involved, suggests that this movement is like an A-movement, and $b a$ is either a Case marker or a Case assigner (e.g., Huang 1982; Huang et al. 2009). ${ }^{16}$

Unlike typical A-movement structures, however, some properties of the $b a$ construction show that the movement involved is an optional movement. First of all, the accusative Case of the $b a$ DP can also be assigned in sentences without $b a$ (cf. 9a and 18). If the movement is considered as Case-driven, this means that the movement is optional. Second, unlike typical A-movement structures such as English passivization, the $b a$ construction does not produce new semantic interpretations that are not available without movement:

a. Zhangsan guyi dashang-le Lisi.

Zhangsan deliberately hit.hurt-PFv Lisi.

'Zhangsan deliberately hit and hurt Lisi.'

b. ?Zhangsan ba Lisi guyi dashang le. (not ambiguous)

Zhangsan BA Lisi deliberately hit.hurt-PFV

'Zhangsan deliberately hit and hurt Lisi.'

(28) a. Joan instructed Mary reluctantly. (Joan/*Mary)

b. Mary was reluctantly instructed by Joan. (Mary/Joan) (Matsuoka 2013)

c. John cleverly has been examined by the doctor. (John/*the doctor) (Jackendoff 1972)

In (27b), $b a$ DP precedes a type of adverbs (commonly called subject-oriented adverbs) that can be construed with either the subject or the object under certain circumstances (Geuder 2004), but in the example provided, the adverb cannot be construed with the underlying object DP. This situation contrasts with English passives in $(28 \mathrm{~b}, \mathrm{c})$, where the adverbs can be construed with the underlying object, which is the surface subject. The contrast between (27) and (28) suggests that whereas English passivization has semantic import, $b a$ DP movement is semantically vacuous. As semantic vacuousness is an essential property of optional movements (cf. Saito and Fukui 1998), this constitutes another reason for treating $b a$ DP movement as an optional movement.

The third reason for regarding this movement as an optional movement is that this movement in general only occurs when it serves as a repair strategy to

$16 \mathrm{Ba}$-DP also has properties of $\mathrm{A}^{\prime}$-movement, in that it tends to be definite or specific (see note 13). 
rescue potentially ill-formed sentences. This can be seen in the contrast between the constructions in (29) (Li 2006):
a. ??Wo ba ge ting-le.
I BA song listen-PFV
'I listened to the song.'
b. Wo ba ge ting-wan-le.
I BA song listen-finish-PFV
'I finished listening to the song.'

In (29a), the verb ting is followed by an aspectual morpheme, which does not count as a PLC element, according to (8), and the sentence is ill-formed. The wellformed (29b), on the other hand, involves a morpheme expressing extent, which counts as a PLC element. ${ }^{17}$ The contrast can be taken to mean that $b a$ constructions that are not derived from underlying structures with potential PLC violations are ill-formed. In other words, $b a$ DP movement does not occur if it does not rescue a potential PLC violation. The situation is complicated somewhat, however, in that this rescuing effect appears to be absent with some types of verbs, according to $\mathrm{Li}$ (2006) and references cited there:

(30) Ta ba Lisi pian-le.

I BA Lisi cheat-PRT

'He cheated Lisi.'

If the $b a$ construction is a repair strategy, one might think that (30) should be ill-formed, just like (29a), since no potential violations of PLC are involved and rescued in (30). Nevertheless, the well-formedness of (30) could be due to the fact that -le is ambiguous, which can be construed as either a perfective aspect marker or a phase marker, depending on the type of verb it occurs with (cf. Lü 1980; Sybesma 1999, among others). Indeed, when we consider infinitive clauses where aspectual markers are not allowed, the rescuing effect is again present. Note also that non-repair-strategy movement structures do not have this effect (cf. 31c,d).
a. *Wo xiang ba Lisi pian.
I want BA Lisi cheat
b. Wo xiang pian Lisi.
I want cheat Lisi.
'I want to cheat Lisi.'
c. Wo xiang bei Lisi pian. (passive construction)
I want BEI Lisi cheat
'I want to be cheated by Lisi.'

17 Following Huang (1984), I assume that in sentences like (29b), wan is a phrasal constituent, at least for the purpose of PF conditions such as the PLC. 
d. Lian Lisi wo dou xiang pian. (lian ...dou focus construction) even Lisi I Dou want cheat 'I want to cheat even Lisi.'

(32) a. Wo xiang ba Lisi pian guolai.

I want BA Lisi cheat come.here

'I want to trick Lisi into coming here.'

b. ??Wo xiang pian Lisi guolai.

I want cheat Lisi come.here

The contrast between (31a), where no PLC element is present, and (32a), where guolai is a PLC element, clearly shows that the $b a$ construction has to involve potential PLC violations, where it serves as a repair strategy. ${ }^{18}$ This fact is reminiscent of the optional movements discussed by Chomsky (2001), object shift to a preverbal position in successive-cyclic A'-movements, and the Scandinavian object shift. According to Chomsky, these structures allow optional movements because lack of movement would incur either a locality condition violation or a deviance at the syntax-semantics interface. ${ }^{19}$

The optionality of the $b a$ DP movement suggests that it is subject to the following general economy principle regulating optional movements (e.g., Fox 1995, Fox 2000; Reinhart 1997; Chomsky 2001):

(33) An optional rule can apply only when necessary to yield a new outcome.

From what we have seen in the previous paragraph, the $b a$ construction indeed appears to be subject to such a principle, in that the movement only takes place if

18 Syntactic properties of verb-resultative compounds constitute further pieces of evidence for treating the $b a$ construction as a repair strategy. Both of the following sentences are well-formed:

(i) a. Ta qi-lei le ma.

he ride-tired PFv horse

'He rode the horse and got tired./He rode the horse and the horse got tired.'

b. Ta ba ma qi-lei le.

he BA horse ride-tired PFV

'He rode the horse and the horse got tired.'

Huang (1984) argues convincingly that in these two sentences, the resultative elements have different syntactic statuses. According to Huang, type (ia) sentences are flexible with regard to the antecedent of the subject of lei (cf. also Huang et al. 2009: 40), whereas type (ib) sentences are not. This contrast suggests that lei in (ia) forms a $\mathrm{V}^{0}$ constituent with $q i$ (called "lexicalization" by Huang 1984), but in (ib), it forms a VP with $q i$, where the identification of the PRO subject for lei is regulated syntactically. This shows that the $b a$ construction is a repair strategy with regard to PLC in sentences like (ib), even though the "repair effects" are obscured by the availability of the lexicalization of VR sequences in type (ia) sentences (which is also a repair strategy, according to Huang).

19 Another possibility for the motivation of the Scandinavian pronominal object shift is the deficient prosodic status of weak pronouns (Richards 2004:39 ff. and references cited therein). 
it serves as a repair strategy. The problem now is how to characterize this repair strategy with our current understanding of Mandarin Syntax.

The HDP settings in Mandarin (22) and LinCon (21), when joined together, are able to provide such a characterization. Consider first the ill-formed (31a). At the derivational stage when the verb is moving, the movement is leftward, as per the TDP setting, and the HDP setting is not violated.<smiles>[Mg][Te]</smiles>

At the stage when the resultant structure is undergoing further merger, the $b a$ DP movement would violate principle (33), in that both the moved and the unmoved structures do not violate the HDP setting: no more than one constituent follows the verb.

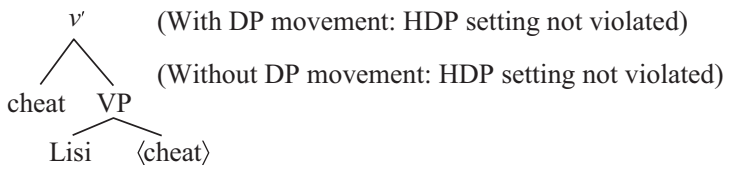

Now consider the well-formed (32a). At the derivational stage when the verb is moving, the movement has to be leftward, under familiar assumptions.

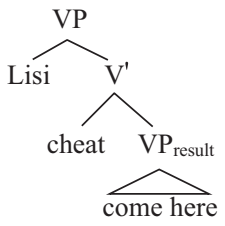

At the next stage, when the resultant structure is undergoing merger, the $b a \mathrm{DP}$ movement would obey the economy principle, since lack of movement would incur the violation of the HDP setting in Mandarin.

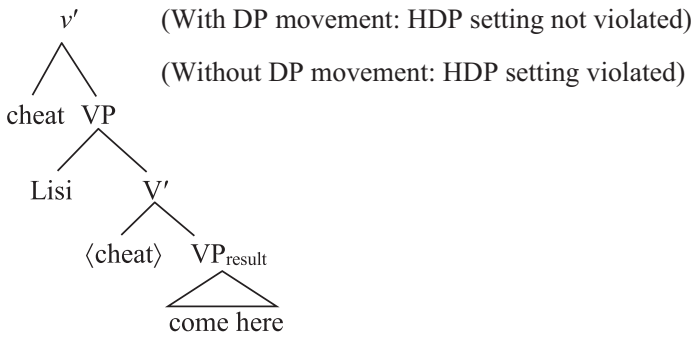


Without LinCon, the contrast between (31a) and (32a) cannot be accounted for by the HDP and the economy principle alone. At the derivational stage of (37), if Lisi does not move, the HDP setting without LinCon is observed. This is because HDP can now only see the verb and its complement VP at this stage, as its DP and VP arguments are merged in earlier derivational stages and are invisible. This would wrongly predict that both (31a) and (32a) are ill-formed because they both violate the economy principle, contrary to fact.

Table 1 Deriving licit and illicit word orders in Mandarin by the HDP under LinCon

\begin{tabular}{|l|l|l|l|}
\hline & $\begin{array}{l}\text { Verb with two } \\
\text { overt postverbal } \\
\text { elements }\end{array}$ & $\begin{array}{l}\text { Bare } \boldsymbol{b a} \\
\text { construction (not } \\
\text { followed by a } \\
\text { PLC element) }\end{array}$ & $\begin{array}{l}\text { Nonbare } \boldsymbol{b} \boldsymbol{a} \\
\text { construction }\end{array}$ \\
\hline $\begin{array}{l}\text { Before } \\
\text { movement }\end{array}$ & $\begin{array}{l}\text { Illicit HDP } \\
\text { violation }\end{array}$ & $\begin{array}{l}\text { No illicit HDP } \\
\text { violation }\end{array}$ & $\begin{array}{l}\text { Illicit HDP } \\
\text { violation }\end{array}$ \\
\hline $\begin{array}{l}\text { After movement } \\
\text { or after next } \\
\text { merger }\end{array}$ & $\begin{array}{l}\text { Illicit HDP } \\
\text { violation } \\
\text { (movement could } \\
\text { occur but does } \\
\text { not occur) }\end{array}$ & $\begin{array}{l}\text { Economy principle } \\
\text { violation }\end{array}$ & $\begin{array}{l}\text { HDP setting } \\
\text { is obeyed; } \\
\text { no economy } \\
\text { principle violation }\end{array}$ \\
\hline
\end{tabular}

\section{Directionality macro- and microparameters at the syntax-PF interface}

Having established LinCon as a descriptive generalization, we now turn to the formal mechanisms that underlie LinCon. I will argue that LinCon and various other properties of the $b a$ construction can be explained by a type of interfacebased theory that determines basic word order by parametric settings that are in effect throughout the derivation.

Works on word order variations generally do not assume this type of interface-based analysis. In the Principles-and-Parameters (P\&P) framework, Merge and Move are parameterized according to HDPs (e.g., Saito and Fukui 1998; Ernst 2002). This approach does not refer to structures that are generated at different stages, because the presented empirical facts can be simply accounted for by regulations on Merge and Move themselves. In the common alternative, the Antisymmetry Theory (Kayne 1994) under the Bare Phrase Structure (BPS) framework (Chomsky 1995), word order is determined by a universal principle at the syntax-PF interface, whereas HDPs are abandoned and replaced by parameters related to syntactic movement and null functional heads. The abandonment of directionality parameters is due to the need to eliminate certain stipulated properties 
of the X-bar theory. The BPS version of the Antisymmetry Theory also conforms to the common observation that order plays no clear role at logical form (LF) or narrow syntax (cf. Chomsky 1995: 334), but this theory still cannot see word order throughout the derivation. ${ }^{20}$

There are reasons, however, to adopt a more powerful interface-based analysis that retains directionality parameters, which are macroparameters because they are not encoded in the lexicon (cf. Huang and Roberts 2017). First, it seems redundant to encode head directionality in narrow syntax, as heads contain features associated with c-selection, and directionality is a consequence of this operation (cf. Richards 2004). Second, as mentioned above, there is no clear evidence that order plays a role in narrow syntax or LF. Third, there is empirical evidence from Scandinavian object shift and scrambling in German that head directionalities determine order not only in the base structure but also at later stages in the derivation. As noted by Richards (2004), Holmberg's Generalization (HG: object movement is contingent on the movement [and thus finiteness] of the lexical verb, see (2)) is only applicable to languages with VO base order, as represented in the following chart:

Table 2 Differences between object-shift and scrambling

\begin{tabular}{|l|l|}
\hline & Nonfinite main verb (no verb movement) \\
\hline Object shift: & \\
Mainland Scandinavian/Icelandic & No $(\mathrm{HG})$ \\
\hline Scrambling: & \\
Dutch/German & Yes \\
\hline
\end{tabular}

The different influences of the verb movement on the possibility of DP movement can be taken to reflect the different base order in the languages. Illicit object shift disrupts the VO base order in Danish and Icelandic, since the verb is not moved and the moved object precedes the verb. On the other hand, scrambling in Dutch and German is allowed with or without verb movement, since in either case, scrambling does not disrupt the base order between the verb and the object DP

20 As pointed out by an anonymous reviewer, another common alternative to the classic views of parameters is what is commonly referred to as the Borer-Chomsky Conjecture (cf. Borer 1984; Chomsky 2001), according to which all parameters are attributable to differences in features of particular items in the lexicon. This view is challenged by the robust evidence of clustering of properties described and predicted by the classic macroparametric view (for recent discussion, see Huang and Roberts 2017). Nevertheless, one corollary of this conjecture is that there are no directionality macroparameters, one implementation of which is developed in the form of Kayne's Antisymmetry Theory. This theory is still assumed by linguists who reject the Borer-Chomsky Conjecture (Biberauer et al. 2014; Huang 2015). Due to these reasons, I will mainly talk about the feasibility of the theory prominently associated with the conjecture, the Antisymmetry Theory, instead of the conjecture itself. 
(in V2 configurations, the base OV order is disrupted, but this disruption is not caused by scrambling). ${ }^{21}$

The typological correlation between head directionality and $\mathrm{HG}$ is unexpected for the Antisymmetry Theory, according to which all languages have the same base order. This correlation is also unexpected for the classic Principles-and-Parameters approach, because directionality parameters in these approaches can only see head directionality at each directionality stage and, therefore, cannot see whether the verb has been moved when the object shift occurs. Nevertheless, it does seem that components of these theories are required: we need HDPs, and these parameters are relevant at the syntax-PF interface.

We thus have strong motivations for a more powerful interface-based approach to word order variations equipped with directionality parameters. There are, still, at least two possible approaches to choose from. One is to assume that the HDP applies at the interface, but it only covers the head-complement linearization (Richards's [2004, 2007, 2008] Parameterized Linear Correspondence Axiom [LCA], Sheehan's [2013] Revised LCA). Head-specifier/adjunct order is still regulated by the Antisymmetry Theory. Such a view is motivated by the following: (i) the common observation that specifiers tend to precede the head in both VO and OV languages (Kayne 1994, Kayne 2004, among others); (ii) the fact that the landing site of the object shift in a VO language is a preverbal position; and (iii) the empirical observation that languages appear to universally obey the Finalover-Final Constraint (FOFC) (Biberauer et al. 2008, Biberauer et al. 2014, among others). ${ }^{22}$ Another possibility is to assume that HDPs apply to head-complement and head-adjunct linearizations at the interface, similarly to what has been assumed in the P\&P framework in narrow syntax. Such a proposal is in line with the view that the right-adjunction analysis of English adjuncts is favorable to the Kaynean leftspecifier-cum-intraposition analysis on conceptual grounds (Ernst 2002: Ch. 4). In what follows, I assume the second approach to LinCon and the $b a$ DP movement.

\subsection{Theoretical assumptions about word order, Merge, and Move}

The main idea behind an interface-based approach to directionality parameters assumed here is the following hypothesis (e.g., Chomsky 1995; Richards 2004):

\section{(38) Symmetrical Syntax Hypothesis (The SSH)}

Syntactic operations/relations make no reference to notions of linear ordering and directionality.

21 A well-known alternative PF-based account of Scandinavian OS is Fox and Pesetsky's (2005) Cyclic Linearization analysis, according to which movements have to obey the ordering established in an earlier phase. As this cited account focuses on universal principles and does not address the question of cross-linguistic ordering variations, it does not have clear predictions for $v \mathrm{P}$ internal movements in other languages, such as the $b a$ DP movement. See Richards (2004, 2007) for detailed discussions of this approach.

22 For some discussions on the empirical issues of this claim in Chinese, see Liao (2017). 
Consider what this means for a head-complement configuration. When Merge occurs, there is no specific ordering information available. Assume that Merge is given all the possible ordering information. At the syntax-PF interface, the surplus of ordering information is reduced by a repair strategy, deletion of information. Assume further that this deletion applies throughout the derivation, which entails LinCon, due to its status as an interface-level mechanism:

(39) The Parameter-setting Preservation Principle (PPP)

HDPs apply throughout the derivation.

Such a procedure can be represented as follows: ${ }^{23}$

(40) Merge and directionality parameters at work: head-complement merger Merge $(\mathrm{V}, \mathrm{O}) \rightarrow\{<\mathrm{V}, \mathrm{O}>,<\mathrm{O}, \mathrm{V}\rangle\}$

$\mathrm{VO}=$ Ignore all $\mathrm{O}>\mathrm{V} \quad$ [i.e., $\{<\mathrm{V}, \mathrm{O}>,<\mathrm{O}, \mathrm{V}\rangle\} \rightarrow\{<\mathrm{V}, \mathrm{O}>\}]$

$\mathrm{OV}=$ Ignore all $\mathrm{V}>\mathrm{O}$ [i.e., $\{<\mathrm{V}, \mathrm{O}>,<\mathrm{O}, \mathrm{V}>\} \rightarrow\{<\mathrm{O}, \mathrm{V}>\}$ ]

Such a procedure derives the word order of $\left[_{\nu \mathrm{P}}\right.$ saw John] instead of ${ }_{{ }_{\nu \mathrm{P}}}$ John saw $]$ in English, and the reverse word order in Japanese. In Mandarin, the VO order is derived by the parameter in (6), which, I assume, can override (38), and regulates the word order of arguments with certain theta roles at the base structure. Since it can override a macroparameter, I assume that it is a microparameter, stated as follows:

(41) Theta-directionality microparametric $\left(\mathrm{TDP}_{\text {micro }}\right)$ settings in Mandarin Object DPs, complements (resultative and goal phrases), and certain cases of DFM expressions follow the lexical verb $(\mathrm{V}>\mathrm{XP}$; XP $=$ complements or certain DFM expressions).

Consider next what happens when obligatory movements (i.e., wh-movement, subject-raising, etc.) occur. Assuming that there is a linearization principle that imposes Spec $>$ head order (e.g., Kayne 1994; Ernst 2002), ${ }^{24}$ an obligatory movement structure in English involves the following derivation:

(42) Merge and directionality parameters at work: obligatory movement in English Merge $(\mathrm{V}, \mathrm{O}) \rightarrow\{<\mathrm{V}, \mathrm{O}>,<\mathrm{O}, \mathrm{V}>\}$

$\operatorname{Merge}\left(\mathrm{O},\left(\mathrm{V}, \mathrm{t}_{\mathrm{o}}\right)\right) \rightarrow\{<\mathrm{O}, \mathrm{V}>\}$

$\mathrm{VO}=$ Ignore all $\mathrm{O}>\mathrm{V}$ [i.e., $\{<\mathrm{V}, \mathrm{O}>,<\mathrm{O}, \mathrm{V}>\} \rightarrow\{<\mathrm{V}, \mathrm{O}>\}]$

23 This formulation is similar to Richards's (2004), which is based on Epstein et al.'s (1998) view of $\mathrm{PF}$ linearization. It differs from these approaches, however, in that it does not involve c-command relations in PF linearization.

24 Following Ernst (2002), I distinguish between adjuncts and specifiers. 
Spec $>$ head $=$ The universal linearization principle of Spec $>$ head order Obligatory movement $=$ Full Interpretation $(\mathrm{FI})^{25}$

According to such a derivation, a sentence like What did John see? is subject to various interface conditions and principles. Although the $\mathrm{V}>\mathrm{O}$ order applies throughout the derivation, a sentence cannot violate Full Interpretation (Chomsky 1986, Chomsky 1995) by leaving uninterpretable features unmatched and unvalued. In addition, the Spec $>$ head principle ensures that when the movement occurs, the landing site is in the preverbal position. These latter two requirements override the VO directionality parameter and thus derive the obligatory movement.

So far, we have not seen the effects of LinCon and PPP, since the configurations involve either nothing that can disrupt the base order or certain more general requirements that override the HDP. The more interesting cases would be those where base order is disrupted but HDP is maintained or those where HDP is maintained only after base order is disrupted. The Scandinavian object shift configuration belongs to the former type of situations. In this type of movement structure, the movement is optional and is associated with the following filters: (i) a language-specific ban on in-situ definite DPs when the lexical verb is moved out of the $v$ P (Chomsky 2001); and (ii) a language-specific requirement for pronouns to be adjacent to the lexical verb (Richards 2004) ${ }^{26}$ Following a slightly modified version of Richards (2004), I assume that the Scandinavian object shift involves the following derivation:

(43) Merge and directionality parameters at work: Scandinavian $O S$

Merge $(\mathrm{V}, \mathrm{O}) \rightarrow\{<\mathrm{V}, \mathrm{O}>,<\mathrm{O}, \mathrm{V}>\}$

$\operatorname{Merge}\left(\mathrm{O},\left(\mathrm{V}, \mathrm{t}_{\mathrm{o}}\right)\right) \rightarrow\{<\mathrm{O}, \mathrm{V}>\}$ (optional movement)

Merge $\left(\mathrm{V},\left[_{\mathrm{TP}} \ldots \mathrm{t}_{\mathrm{v}} \ldots\right]\right) \rightarrow\{<\mathrm{V}, \mathrm{TP}($ containing $\mathrm{O})>,<\mathrm{TP}($ containing $\mathrm{O}), \mathrm{V}>\}$

$\mathrm{VO}=$ Ignore all $\mathrm{O}>\mathrm{V}$ [i.e., $\{\langle\mathrm{V}, \mathrm{O}\rangle,<\mathrm{O}, \mathrm{V}\rangle\} \rightarrow\{<\mathrm{V}, \mathrm{O}\rangle\}]$

Spec $>$ head $=$ The universal linearization principle of Spec $>$ head order

$\mathrm{V}\left[{ }_{\mathrm{TP}} \ldots \mathrm{t}_{\mathrm{v}} \ldots\right]=$ Ignore all $\mathrm{TP}>\mathrm{V}$ [i.e., $\{<\mathrm{V}, \mathrm{TP}>,\langle\mathrm{TP}, \mathrm{V}>\} \rightarrow\{<\mathrm{V}, \mathrm{TP}>\}]$

Filters: (i) $*\left[_{v P} \mathrm{t}_{v} \mathrm{DP}_{\text {def }}\right]$, (ii) $* \mathrm{~V} \mathrm{XP} \mathrm{t}_{\mathrm{v}}$ pronoun

According to such a derivation, a Scandinavian object shift configuration is subject to a set of language-specific filters, but not the Principle of Full Interpretation with regard to feature matching. As the movement is not

25 Richards (2004) adopts a phase-based analysis of directionality parameters and treats them as nonviolable parameters within the $v \mathrm{P}$ phase. It is not clear how this approach can account for the full range of $v \mathrm{P}-$ level movements cross-linguistically, including the $b a$ DP movement. I will therefore adopt the view that FI is a more general constraint than can override directionality parameters.

26 It is not clear why full definite DPs are allowed to stay in situ while pronouns cannot. It seems that the economy condition in (33) has to be relaxed with regard to at least some types of optional movement. 
subject to feature matching with a mandatory [EPP], it is subject to the $\mathrm{V}>\mathrm{O}$ parametric setting, which applies throughout the derivation, as per PPP. As a consequence, the $\mathrm{V}>\mathrm{O}$ setting derives the base order of $\mathrm{V}>\mathrm{O}$ in Scandinavian languages, as well as the requirement that object shift must be accompanied by V-to-C movement, since the lack of verb movement would induce surface $\mathrm{O}>\mathrm{V}$ order.

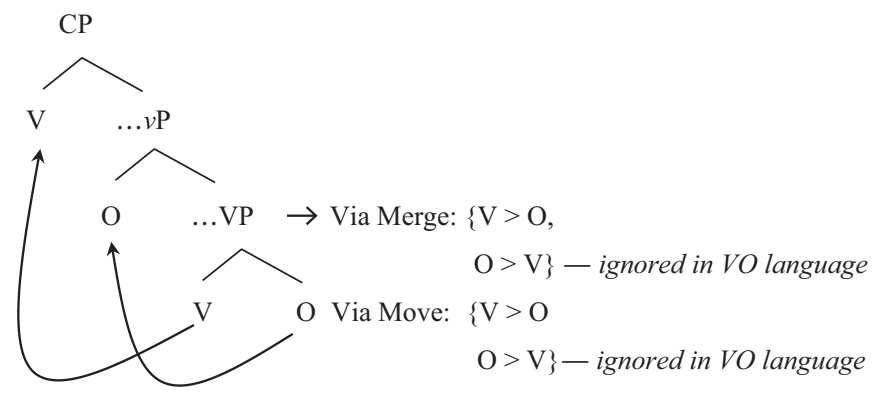

The Scandinavian object shift thus illustrates LinCon and PPP at work, since the HDP sees the base order as well as the derived order. The Scandinavian version of LinCon is thus accounted for. ${ }^{27}$

\subsection{Deriving the $b a$ DP movement structure}

Consider now the $b a$ DP movement, where the base order is disrupted but the HDP setting is maintained. In this movement structure, word order is regulated by directionality microparameters and the directionality macroparameter, since there are exceptions to the macroparameter. ${ }^{28}$ One such microparameter is (41), the TDP ${ }_{\text {micro }}$, repeated below:

\section{$T D P_{\text {micro }}$ settings in Mandarin}

Object DPs, complements (resultative and goal phrases), and certain cases of DFM expressions follow the lexical verb $(\mathrm{V}>\mathrm{XP}$; XP $=$ complements or certain DFM expressions).

The other parameter is an $\mathrm{HDP}_{\text {macro }}$, of which two versions have been discussed in (7) and (22). Suppose, following Baker (2008) and Robert (2014), that microparameters can override macroparameters, the latter acting as elsewhere conditions, we can simply state the HDP in Mandarin as follows:

27 I assume V-to-C movement passes through intermediate landing sites at the edge of the $v \mathrm{P}$ phase, so PPP is able to evaluate the shape of the VO order in the $v$ P phase at Spell-Out at this stage.

28 For recent discussions on micro- and macroparameters, see Robert (2014) and Huang and Roberts (2017). For expository reasons, I only distinguish between micro- and macroparameters. The microparameters discussed in the text may be regarded as mesoparameters in their approach. 
(46)

The HDP ${ }_{\text {macro }}$ setting in Mandarin (final version)

If an XP is a $v \mathrm{P}$-level expression, $\mathrm{XP}>\mathrm{V}$. The setting can be violated once, but no more than once. ${ }^{29}$

With these parametric settings, I propose that the $b a$ DP movement in sentences like (14b) involves the following derivation:

(47) Merge and directionality parameters at work: ba DP movement

$\operatorname{Merge}(\mathrm{V}, \mathrm{PP}) \rightarrow<\mathrm{V}, \mathrm{PP}>$

$\operatorname{Merge}(\mathrm{O},(\mathrm{V}, \mathrm{PP})) \rightarrow\{<\mathrm{O},<\mathrm{V}, \mathrm{PP}>>\}$

$\left.\operatorname{Merge}\left(\mathrm{V},{ }_{\mathrm{VP}} \mathrm{O},\left(\mathrm{t}_{\mathrm{v}}, \mathrm{PP}\right)\right]\right) \rightarrow\{<\mathrm{V},<\mathrm{O}, \mathrm{PP}>>\}$

$\left.\operatorname{Merge}\left(\mathrm{O},{ }_{v^{\prime}}, \mathrm{V}\left[{ }_{\mathrm{VP}} \ldots \mathrm{t}_{\mathrm{o}} \mathrm{PP} \ldots\right]\right]\right) \rightarrow\{<\mathrm{O},<\mathrm{V}, \mathrm{PP}>>\}$ (optional movement)

$\mathrm{V} \mathrm{PP}{ }_{\text {base }}=$ Lexically specified order under the $\mathrm{TDP}_{\text {micro }}$ setting in Mandarin

$\mathrm{O} \mathrm{V}^{\prime}=$ thematic hierarchy theme $>$ result

$\mathrm{V}\left[{ }_{\mathrm{VP}} \ldots \mathrm{O} \mathrm{t}_{\mathrm{v}} \ldots\right]=$ Movement associated with accusative case licensing

(Larson 1988); lexically specified order under the $\mathrm{TDP}_{\text {micro }}$ setting in Mandarin.

Spec $>$ head $=$ The universal linearization principle of Spec $>$ head order

$\mathrm{O}$ V PP $=$ Ignore all V followed by two constituents (HDP in Mandarin)

[i.e., $\{<\mathrm{V},<\mathrm{O}, \mathrm{PP}>>,<\mathrm{O},<\mathrm{V}, \mathrm{PP}>>\} \rightarrow\{<\mathrm{O},<\mathrm{V}, \mathrm{PP}>>\}$ ]

In this derivation, the $b a$ DP movement structure is regulated by the TDP ${ }_{\text {micro, }}$, the HDP, as well as several other mechanisms that underlie V-to-v movement, merger of the specifier, and the hierarchy of VP-internal constituents. Similar to the Scandinavian OS, the $b a$ DP movement is not subject to an obligatory presence of an [EPP] feature, so the movement or non-movement is regulated by the HDP (XP $>\mathrm{V}$, only one violation is allowed), which is in effect throughout the derivation. The result is that the HDP regulates word order in the base structure with regard to those not covered by the TDP ${ }_{\text {micro }}$, in addition to requiring optional ba DP movement to occur when non-movement would violate the HDP.

29 As noted by two anonymous reviewers, it is not clear why a parameter setting can be specified as violable to some degree. Since the syntax-PF interface is still a mostly uncharted territory, at present, I do not have a concrete answer for this other than some speculative remarks. There may be two driving forces for the violability of PF directionality specifications. One is the languagespecific constraints on the permissible weights of constituents in non-canonical positions (cf. Ernst 2002), which may constrain the number of violations of HDPs. The other is the languagespecific constraints on the availability and robustness of optional movements (cf. note 26), which may force HDPs to be violated to different degrees. I leave formalization of these constraints for future research. Note that these matters do not affect the validity of the proposal that HDPs are macroparameters that apply throughout the derivation. 


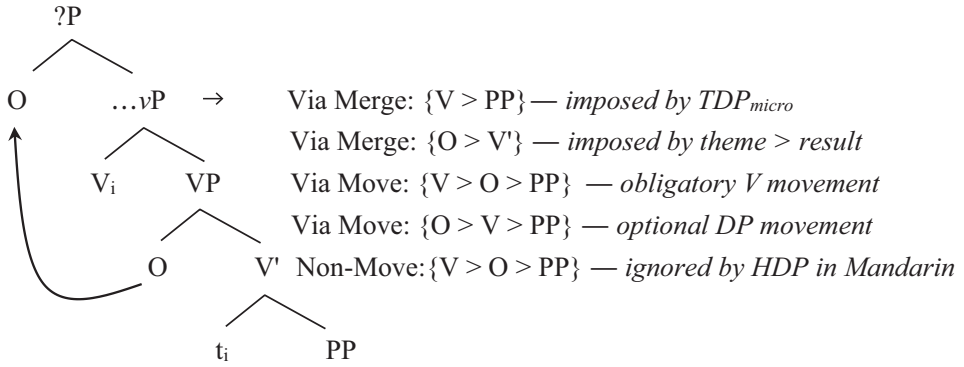

The $b a$ DP movement in the current analysis thus accounts for LinCon. Mandarin is mostly a head-final language at the $v \mathrm{P}$ level, because of the XP $>\mathrm{V}$ macroparameter. The same macroparameter also regulates whether ba DP movement takes place or not. Only movement would produce a word order that satisfies the HDP setting.

Table 3 Deriving licit and illicit word orders in Mandarin by the HDP under SSH

\begin{tabular}{|l|l|l|l|}
\hline & $\begin{array}{l}\text { Verb with two } \\
\text { overt postverbal } \\
\text { elements }\end{array}$ & $\begin{array}{l}\text { Bare } \boldsymbol{b} \boldsymbol{a} \\
\text { construction (not } \\
\text { followed by a } \\
\text { PLC element) }\end{array}$ & $\begin{array}{l}\text { Nonbare } \boldsymbol{b} \boldsymbol{a} \\
\text { construction }\end{array}$ \\
\hline $\begin{array}{l}\text { Before } \\
\text { movement }\end{array}$ & $\begin{array}{l}\text { HDP is } \\
\text { overridden by } \\
\text { TDP }\end{array}$ & $\begin{array}{l}\text { HDP is } \\
\text { overridden by } \\
\text { TDP }\end{array}$ & $\begin{array}{l}\text { HDP is } \\
\text { overridden by } \\
\text { TDP }\end{array}$ \\
\hline $\begin{array}{l}\text { After movement } \\
\text { or after next } \\
\text { merger }\end{array}$ & $\begin{array}{l}\text { Illicit HDP } \\
\text { violation } \\
\text { (movement could } \\
\text { occur but does } \\
\text { not occur) }\end{array}$ & $\begin{array}{l}\text { Economy } \\
\text { principle violation }\end{array}$ & $\begin{array}{l}\text { No HDP } \\
\text { violation; } \\
\text { no economy } \\
\text { principle violation }\end{array}$ \\
\hline
\end{tabular}

\subsection{Consequences}

If the current syntax-PF interface-based analysis for the $b a \mathrm{DP}$ movement is on the right track, it may shed some light on some of the various other properties of the $b a$ construction studied in the literature.

\subsubsection{The projection hosting the ba DP movement}

The optional movement structure of the $b a$ construction adopted here may help settle the debate with regard to the projection that hosts the DP movement (Huang et al. 2009; Kuo 2010; Paul 2015). Since the $b a$ DP movement is an optional movement (cf. Section 2.2) and since $b a$ cannot be present when movement does not take place (cf. (26)), the most straightforward analysis would be to treat $b a$ as a by-product of the DP movement and place the optional movement-triggering [EPP] feature on a head that is independently required in the architecture of grammar. 
Under this view, there are two candidates for the landing site of the $b a$ DP: (i) Spec, $v$ P; and (ii) Spec,VoiceP. Since the canonical ba construction requires a transitive predicate and an agent argument, ${ }^{30}$ but not vice versa, it can be argued that the $b a$ construction has a transitive structure as its input and is therefore licensed by a Voice head (cf. Kratzer 1996; Alexiadou 2014, among others). ${ }^{31}$ In addition, since the agent argument is in its canonical Spec,TP position, the licensing head should be a subtype of the active Voice head, with the Voice head licensing the agent argument. How does a single Voice head license two arguments? This could be due to the presence of multiple features on the Voice head. One the one hand, the external argument is licensed by a feature associated with c-selection. On the other hand, the ba DP movement is licensed by an optional [EPP] feature, which triggers the movement of the direct object from its VP-internal position. The result is a multiple-specifier structure:

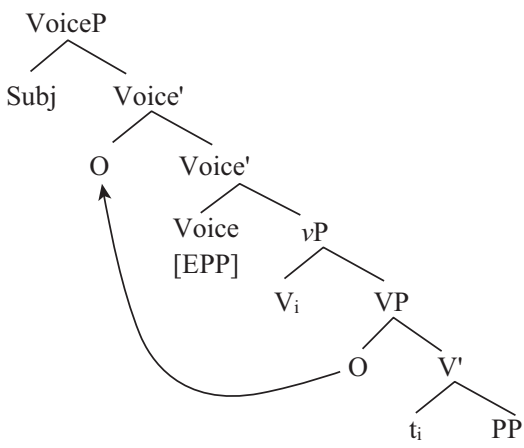

Previous analyses fall into two categories in terms of the structural position of the ba DP: (i) the Spec, $v$ P position (Huang et al. 2009), and (ii) a $v$ P-external position, where the $b a$ DP occurs between $v \mathrm{P}$ and the projection that hosts the external argument (Kuo 2010; Paul 2015). These two types of analyses can be represented as follows $(\mathrm{XP}=$ the projection hosting the external argument; $\mathrm{YP}=$ the projection that is situated between $\mathrm{XP}$ and $v \mathrm{P})$ :
a. $\left[{ }_{\mathrm{XP}}\right.$ Subject $\left.\mathrm{X}\left[{ }_{v \mathrm{P}} \mathrm{DP} \mathrm{P}_{\mathrm{i}} v \ldots \mathrm{t}_{\mathrm{i}}\right]\right]$
b. $\left[{ }_{\mathrm{XP}}\right.$ Subject X $\left.\left[_{\mathrm{YP}} \mathrm{DP}{ }_{\mathrm{i}} \mathrm{Y}\left[{ }_{v \mathrm{P}} v \ldots \mathrm{t}_{\mathrm{i}}\right]\right]\right]$

30 The fact is obscured by the presence of causative ba sentences (Sybesma 1999; Li 2006, etc.). In general, however, the $b a$ construction needs an agent argument and a transitive predicate:

(i) a. *Zhangsan ba Lisi ku le liang ci. (Intransitive predicate)

Zhangsan BA Lisi cry PFV two time

'Intended: Zhangsan caused Lisi to cry twice.'

b. *Diannao ba wo huai le liang ci. (Intransitive predicate, no agent or causer argument) computer BA I malfunction PFV two time

'Intended: The computer malfunctioned on me twice.'

31 I thank an anonymous reviewer for some helpful suggestions about the VoiceP analysis. 
While the first approach seems parsimonious, since it does not require an additional projection that is not found in the common approaches to verbal projections, it cannot easily account for why the $b a$ construction requires an external argument and a transitive predicate. It has to stipulate that $\mathrm{X}$ requires a transitive complement, but $\mathrm{X}$ itself does not trigger the $b a \mathrm{DP}$ movement. The second approach is compatible with an analysis that associates ba DP movement with a functional head that requires a transitive predicate, since the $\mathrm{Y}$ head c-commands $v$ and may have c-selection relations with the latter. However, it is unclear why $\mathrm{Y}$ is only present when the PLC effect (8) is present. ${ }^{32}$

\subsubsection{The syntactic category of $b a$}

Previous studies of the syntactic category of $b a$ are inconclusive. While most of the recent formal analyses treat $b a$ as a head of a functional projection that dominates $v$ P (e.g., Sybesma 1999; Huang et al. 2009; Kuo 2010; Paul 2015), Huang et al. (2009) also acknowledges the possibility that $b a$ may form a constituent with the following DP. The present analysis is compatible with either constituency analysis.

The main argument for the $v \mathrm{P}$-dominating functional category that hosts $b a$ is the fact that the post- $b a$ DP and the VP seem to form a constituent, based on the coordination test (Huang et al. 2009):

(51) Ta ba [men xi-hao], [chuanghu ca-ganjing]-le.

He BA door wash-finish window wipe-clean-sFP

'He washed the door and wiped the windows clean.'

If this analysis is correct, it could mean that there is an additional VoiceP shell, where the higher Voice head hosts $b a$ and assigns accusative Case to the $b a \mathrm{DP}$ :

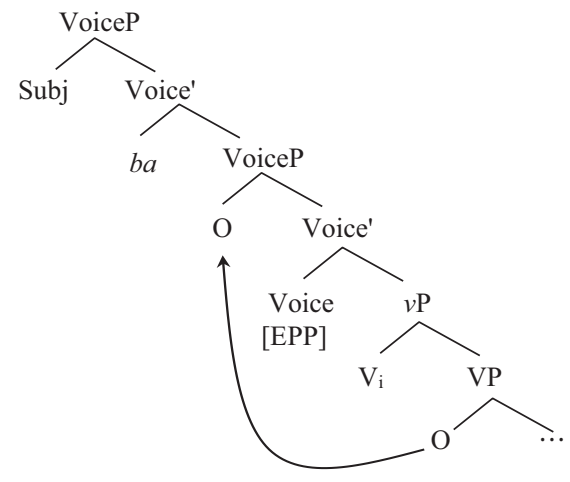

32 A potential argument for YP is the optional presence of the morpheme gei in the $b a$ construction, as noted by Tang (2001) and Kuo (2010). However, Huang (2015) notes that gei can also occur in intransitive sentences. This suggests that gei might not be an ingredient of the $b a$ construction. 
Alternatively, $b a$ could be regarded as forming a constituent with the $b a$ DP, considering the possibility to prepose the [ba DP] constituent (Huang et al. 2009):

(53) $\mathrm{Ba}$ [zhe-kuai rou], ni xian qie-qie ba!

BA this-CL meat you first cut-cut SFP

'Cut the meat first!'

In this sentence, [ba DP] is likely to be a constituent at the Spec,VoiceP position. There is thus no need for a VoiceP shell in (53), so the structure in (49) is sufficient.

\section{Cross-linguistic perspectives: Archaic Chinese and Bambara}

The interface-based account of word order leads to some cross-linguistic predictions. Here, I address two of them. First of all, since the HDP setting in (46) is stated in terms of a gradient-violable condition, it is predicted that there are languages that allow two violations. Second, the existence of HDP setting and TDP ${ }_{\text {micro }}$ settings leads to the prediction that there are languages with mirror-image word order with respect to Mandarin. Both of these predictions are borne out.

\subsection{Archaic Chinese}

Archaic Chinese $(\mathrm{AC})^{33}$ is another language where the HDP setting conflicts with the TDP ${ }_{\text {micro }}$ settings. According to the following word order facts of nominal and verbal expressions, AC patterns somewhat like a head-final language:

(54) a. Modifiers of nominals always precede the head noun.

b. Most postverbal adjuncts or argumental PPs can also occur preverbally.

c. There are some preverbal-only adjuncts (e.g., wei[為]-PPs) and certain $y u$ [於]-PPs) (Wei 1993; Peyraube 1996).

d. There cannot be more than one postverbal PP element (Benett 1981: 84; Wei 1993; Zhang 2002, etc.).

Despite these facts, AC differs from modern Mandarin in several aspects that suggest a different HDP setting. First of all, AC allows a wide range of postverbal adjuncts and allows two postverbal constituents if one of them is the direct object:

$$
\begin{aligned}
& \text { a. 投 其 首 於 寧風 之 } \text { 棘 上 } \\
& \text { tou qi shou yu ningfeng zhi ji shang } \\
& \text { throw his head at Ningfeng Poss thorn top } \\
& \text { '(he) throw his head into a thorn tree near Ningfeng.' } \\
& \left(5^{\text {th }} \mathrm{C} \text {. BCE; Zuozhuan }\right)
\end{aligned}
$$

33 There are actually several stages of Archaic Chinese, as this is a long period. For expository reasons, I will use AC to refer to the period that is before the Qin dynasty and after the Shang dynasty and use late AC (LAC) to refer to the period of Chinese in the two Han dynasties. 
b. 召 虞人 以 弓

zhao yuren yi gong

call officer with bow

'Call an officer with a bow.'

( $5^{\text {th }}$ C. BCE; Zuozhuan $)$

Second, as noted by Benett (1981), Mei (1990), and Wei (1993), among others, the counterparts of the $b a$ construction (marked by $y i$ [以]) in AC are much less robust than in the later stages of Chinese languages. Both Benett and Mei note that placement verbs can occur in $y i$-constructions in late Archaic Chinese (LAC) and early Middle Chinese, as in (56), but not in earlier (Pre-Qin) stages of AC.
以弟子一人
投 河 中
yi dizi yi ren
tou he zhong
YI disciple one person throw river middle
'Throw a disciple into the river.'

$\left(1^{\text {th }}\right.$ C. BCE; Shiji $)$

Third, in some cases, as noted by Aldridge (2012), the "disposal" $y i$ DP in AC can occur postverbally, in contrast to its counterpart in modern Mandarin:

$\begin{array}{llll}\text { 子路, 人 告 之 } & \text { 以 有 過 } \\ \text { Zilu, ren gao zhi yi you guo } \\ \text { Zilu person tell him } \text { YI have error }\end{array}$

'Zilu, someone told him he made a mistake.'

$\left(4^{\text {th }} \mathrm{C} . \mathrm{BCE} ;\right.$ Mencius $)$

These three properties of AC, taken together, suggest that the head-final HDP setting in AC is gradient and allows two violations if at least one postverbal element is a DP. More specifically, assuming that PPs are heavier than DPs under PF linearization (cf. Ernst 2002: 227), the HDP setting in AC then can be stated as follows:

(58) The HDP setting in $A C$

If an $\mathrm{XP}$ is a $v \mathrm{P}-$ level expression, $\mathrm{XP}>\mathrm{V}$. The setting can be violated twice if at least one violating element is lighter than a PP, but no more than twice. ${ }^{34}$

This accounts for (54d) and the well-formedness of (55). The lack of $y i$-constructions of the type in (56) in pre-Qin AC can be accounted for by the economy principle in (33). More specifically, since the $y i$-DP movement does not repair any violations of the HDP setting in AC just given, it should not take place.

34 H.-T. Thomas Lee (personal communication) informs me that in the early stages of first language acquisition in Mandarin, children freely allow two postverbal elements in a sentence, even though preverbal adjuncts are correctly placed in the preverbal position. This could mean that the HDP setting at this stage is the same as the HDP setting in AC, and that the $b a$ DP movement, as well as other types of repair strategies, have not been acquired. I leave implications of this issue for future research. 
(59)

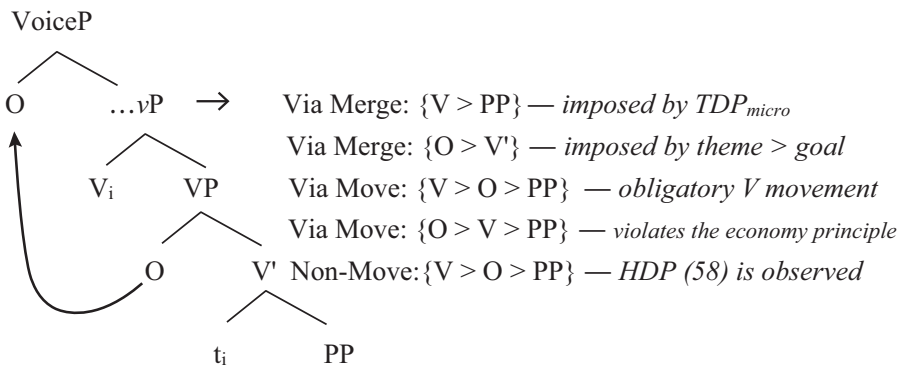

The acceptability of examples like (57) is again due to the HDP setting. Since the verb can be followed by two constituents if at least one of them is light, the sequence V DP $y i$-DP is legitimate. ${ }^{35}$

Note that this analysis crucially relies on the SSH (38) and the PPP (39). This is because the HDP has to be able to see the derivational history in order to see how many elements are merged in a VoiceP so it can rule out two postverbal PPs and allow $(55) .^{36}$

The situation is slightly different in LAC, where the direct object can optionally move in (56). This appears to be a case of free variation. Since little is known about free variation, I tentatively propose the following HDP setting for LAC:

(60) The HDP setting in LAC

If an $\mathrm{XP}$ is a $v \mathrm{P}$-level expression, $\mathrm{XP}>\mathrm{V}$. The setting can be violated once, and no more than twice, and cannot be violated twice if both violating elements are PPs. It is unspecified whether it can be violated in other cases.

According to this setting, LAC allows some freedom as to whether a [V DP PP] sequence is legitimate or not, hence the presence of optional movement in (56).

(61)

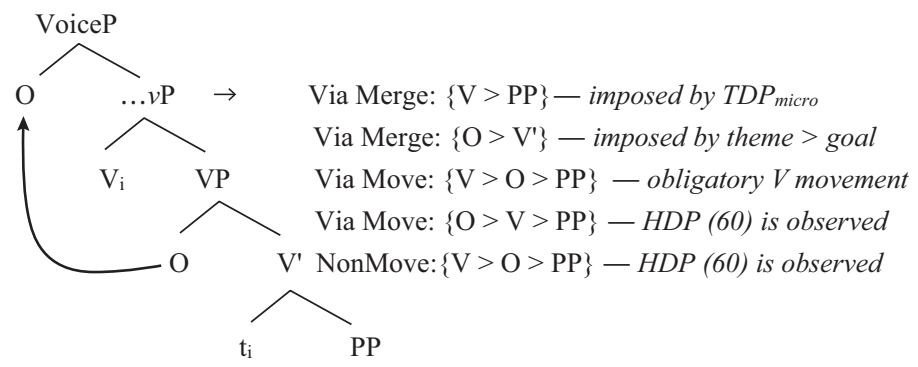

35 There are two possible analyses for (57). One involves rightward movement of the $y i$-phrase from a VP-internal position (i.e., $\left[\left[_{\mathrm{VP}} \mathrm{V} \mathrm{t}_{\mathrm{i}} \mathrm{DP}\right]\right.$ yi $\left.\left.\mathrm{DP}_{\mathrm{i}}\right]\right)$. The other involves a leftward VP movement (i.e., $\left.\left[\mathrm{VP}_{\mathrm{i}}\left[y i \mathrm{DP} \mathrm{t}_{\mathrm{i}}\right]\right]\right)$, as proposed by Aldridge (2012). Either analysis is compatible with the HDP setting for AC proposed here.

36 See Section 5 for alternative approaches to the word order facts in AC. 
This kind of optional movement analysis is also contingent on an interface-based approach to word order linearization. Without such an approach, it is difficult to explain why, in LAC, the yi DP movement is possible in sentences with two postverbal constituents in the base structure but not in sentences with only one postverbal constituent in the base structure (Mei 1990).

\subsection{Bambara}

Bambara is a language the HDP setting and TDP ${ }_{\text {micro }}$ settings of which make it resemble a mirror image of Mandarin. According to Koopman (1992) and Creissels (2005), its word order is rigid and has the pattern depicted in (62) and (63):

$$
\left(\operatorname{AdvP} / S^{\prime}\right) \text { NP1 INFL (NP) V (PP) (ADV) } S^{\prime}
$$

(63) a. There can only be one NP before the verb.

b. Any postverbal arguments must be realized as PPs, and vice versa.

If we focus on the Infl $>\mathrm{V}$ and the $\mathrm{V}>\mathrm{PP}$ and $\mathrm{V}>\mathrm{Adv}$ order, it appears that Bambara is basically a head-initial language inside a verbal structure. However, when we take note of the $\mathrm{O}>\mathrm{V}$ order, it appears like a head-final language.

Under the current interface-based analysis, (62) and (63) are easy to account for. Based on available empirical facts, I propose that Bambara has the following parameter settings:

(64) The HDP setting in Bambara

If an $\mathrm{XP}$ is a $v \mathrm{P}$-level expression, $\mathrm{V}>\mathrm{XP}$. The setting can be violated once, but no more than once.

(65) $\mathrm{TDP}_{\text {micro }}$ setting in Bambara

Object DPs precede the lexical verb $(\mathrm{O}>\mathrm{V})$.

These parameter settings can directly derive the word order facts in Bambara. What distinguishes Bambara and Mandarin is the directionality settings of the macro- and microparameters. Bambara facts thus offer some support for a mixedparameter approach adopted in this article. ${ }^{37}$

In sum, under the interface-based approach, the cross-linguistic facts are accounted for as follows:

37 Koopman (1992) argues for an alternative analysis, where the direct object moves to the leftperiphery spec-of-VP to receive accusative case. Her analysis is mainly based on the assumption that languages must be underlying head-initial or head-final, and no mixed parameter settings are allowed. Furthermore, it is based on the Case transmission parameter, according to which only the tail of the chain can assign in Bambara. The present account is simpler than this alternative approach since the former requires no movement and can offer a principled account of crosslinguistic variations. 
Table 4 Some shape-preservation effects and their analyses

\begin{tabular}{|l|l|l|}
\hline $\begin{array}{l}\text { Facts and } \\
\text { analyses }\end{array}$ & Word order facts & Analyses \\
\hline Modern Mandarin & $\begin{array}{l}\text { Generally head-final; } \\
\text { Ba DP movement is robust, but } \\
\text { disallowed if PLC is satisfied; } \\
\text { Rightward DP movement } \\
\text { or leftward VP movement } \\
\text { impossible; }\end{array}$ & $\begin{array}{l}\text { Gradient HDP setting; } \\
\text { TDP setting; } \\
\text { Move to satisfy PPP; } \\
\text { Move can be barred } \\
\text { by the economy } \\
\text { principle }\end{array}$ \\
\hline expression
\end{tabular}

\section{Alternative approaches}

In Section 3, I have briefly discussed alternative approaches to cross-linguistic word order variations. In what follows, I compare those approaches to the current account in more detail.

\subsection{Parameterized Merge}

One of the commonly adopted view of word order variations since the late 1990s is an updated version of the directionality macroparameters (e.g., Saito and Fukui 1998; Ernst 2002), where the parameters do not refer to bar levels but to projecting and non-projecting elements in Merge operations. This approach attempts to capture the correlations between head-complement ordering and head-adjunct ordering, as long as head-specifier ordering is properly defined and excluded from 
the HDPs. For example, the fact that scrambling occurs in Japanese-like languages and heavy NP shift occurs in English-like languages, but not vice versa, has been attributed to the HDP settings of these languages (Saito and Fukui 1998). On the other hand, the fact that complements and $v \mathrm{P}$ - (or PredP) or VP-level adjuncts generally share the same directionality properties has also been attributed to directionality parameters (Ernst 2002: 166 ff.).

This theory of parameterized Merge (PM) regulates each Merge operation according to the syntactic features of the participating members of the Merge. In this theory, the leftward adjuncts in Mandarin are regulated by an HDP (C-Dir in Ernst's terms), but the postverbal elements are regulated by an exceptional parameter setting. In general, Mandarin word order facts can be accounted for. However, it is not able to see what has already happened in the merging elements. As such, under the assumption that syntactic structures are binary-branching, the theory cannot account for the PLC (8), the repair-strategy effect of the $b a$ construction in (31), as well as the PLC-esque constraint in AC in (54d), since the configurations involve at least two Merge operations. In order to accommodate the PLC under this theory, an additional output condition that is independent of the directionality parameters is required. Such a requirement brings redundancy to the PM theory.

\subsection{The Antisymmetry account}

Another common view of word order variation since the mid-1990s, which is often called the Antisymmetry Theory, denies the existence of HDPs and attributes all word order variations to parameters regulating hierarchical relations, such as c-command and the timing of the merger (e.g., Kayne 1994, Kayne 2004; Biberauer et al. 2014). The approach aims at simplifying the architecture of grammar by reducing the number of types of parametric variations. According to this view, specifier $>$ head $>$ complement order corresponds to the in-situ word order, whereas head-final configurations correspond to movement structures. Furthermore, consistent head-final order is derived by "roll-up", where complements are moved and, subsequently, categories containing the complements are moved.

$$
\left.{ }_{\mathrm{CP}}\left[{ }_{\mathrm{TP}} \nu \mathrm{P}_{\mathrm{j}}\left[{ }_{\mathrm{T}^{\prime}} \mathrm{T} \mathrm{t}_{\mathrm{j}}\right]\right]_{\mathrm{i}}\left[\mathrm{C}_{\mathrm{C}^{\prime}} \mathrm{C} \mathrm{t}_{\mathrm{i}}\right]\right]
$$

There are two possible implementations of the Antisymmetry Theory to account for the word order facts in Mandarin and AC discussed above. According to one implementation, adjuncts always precede their host in the base structure (Ernst 2002: 191; Huang 2006b, Huang 2015). ${ }^{38}$ Accordingly, the English sentence Lisi eats noodles with a fork and its Mandarin counterpart have the following base structure:

38 This approach is entertained and later abandoned by Ernst in favor of the parameterized Merge approach mentioned above. 
(67)

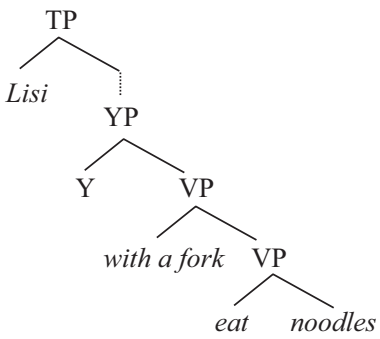

What sets Mandarin apart from English is the fact that the lower VP has to move to a position just above with a fork in English, but it cannot do so in Mandarin. AC, according to this view, is like English, in that the movement is possible.

According to another implementation, what have been regarded as adjuncts in classic approaches may have the status of oblique arguments in certain languages and of leftward adjuncts in other languages (Djamouri et al. 2013). More specifically, while English-type languages are unconstrained with regard to the number of VP-shell structures they allow in a sentence, the parametric setting of Mandarin does not allow any VP-shell structure as far as the so-called adjuncts are concerned, and the relevant setting in AC allows one VP-shell structure in a sentence. Therefore, a sentence like Lisi eats noodles with a fork and its counterpart in AC have a VP-shell structure as in (68), but its counterpart in Mandarin has a left-adjunction structure as in (67).

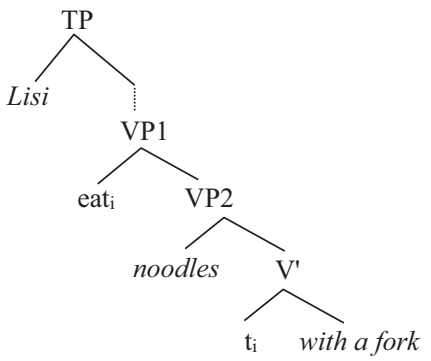

In addition to certain conflicts with established theoretical assumptions and certain empirical issues with word order facts in $\mathrm{AC}$, none of these approaches are able to account for the LinCon effects in Mandarin without additional theoretical machinery. As noted by Aldridge (2012) and Djamouri et al. (2013), Huang's "VP-movement parameter" approach cannot account for the ban on two or more postverbal PPs in AC (54d), as well as various idiosyncratic distributions of postverbal PPs in AC. There is also no straightforward way to derive the PLC and the repair strategy effect of the $b a$ construction. Although one may assume that in the Mandarin counterpart of the sentence John put the book on the table, a movement-triggering feature ${ }^{\wedge}$ on a light verb is present to force the movement of 
the book because the verb is ditransitive, it is far from clear why only ditransitive verbs have this feature, why it is not the whole complement of the light verb that is moved, and how the minus setting of the VP-movement parameter is connected to this type of DP movement. Furthermore, even if the above issues can be resolved, this account fails to account for the fact that this movement has properties of voice and case marking, unlike the ${ }^{\wedge}$-triggered movement in other languages with typical OV orders.

Djamouri et al.'s "VP shell parameter" approach conflicts with Larson's (1988) assumption that oblique arguments are regulated by a thematic hierarchy, which is incompatible with a left adjunction analysis, ${ }^{39}$ and it also does not address the PLC-related facts discussed above. One may, again, postulate that the ${ }^{\wedge}$ feature is present only on ditransitive verbs, but such a solution cannot explain why such feature specifications are only present in languages with no VP shell structures with regard to adjuncts.

\section{Summary and outlook}

Syntactic movement may be triggered or conditioned by PF linearization conditions. The fact that $b a$-marked DP movement in Mandarin is generally obligatory whenever the verb is followed by additional material in a $v \mathrm{P}$ suggests that Mandarin is no different in this respect. In order to account for this type of movement, I have argued for the following points:

(69) a. Mandarin obeys a soft linearization consistency constraint, according to which a verb is head-final throughout the derivation, but it can be overridden once if more specific linearization specifications are in effect.

b. This constraint is a part of the head directionality macroparameter in Mandarin.

c. The ba-marked DP movement is a repair strategy for this constraint. Whether the movement occurs or not is contingent on this constraint.

d. As a directionality macroparameter under the SSH, the HDP is operative throughout the derivation.

e. AC is subject to a slightly different HDP setting, whereas Bambara is subject to an almost opposite HDP setting.

This analysis departs from previous studies of Mandarin in that it adopts an SSH-based approach. Under the widely assumed BPS framework and the binarybranching analysis of syntax, this seems to be the only plausible approach, as neither the parameterized Merge approach nor the Antisymmetry approach capture the PLC straightforwardly.

39 For additional criticisms of the VP-shell analysis of adjuncts, see Ernst (2002: $178 \mathrm{ff}$.). 
There are some unresolved issues that come with this new approach to Mandarin syntax. First of all, it is not entirely clear how an SSH-based theory can be constrained. It is certainly more powerful than the parameterized Merge theory, in that it can see the word order throughout the derivation. This leads to the prediction that the LinCon effect can be detected to the extent that optional movement is allowed in a given language. So far, we have only seen two different kinds of optional movement associated with LinCon: one is the Scandinavian OS, whose landing site is higher than sentence adverbials, and the other is the $b a$ DP movement, whose landing site is lower. This cross-linguistic variation needs to be more closely and extensively studied, as well as its relevance to the Phase theory (Chomsky 2000 et seq). Second, the current SSH-based approach offers no straightforward account for cases that involve optional movements that behave like free variations, where both moved and non-moved sentences are well-formed, as has been observed in LAC (see Section 5) and Cantonese (Matthews and Yip 1994: 122). Third, many of the Chinese languages, including Cantonese (Tang 2015) and Taiwanese Southern Min (Lee 2008), allow different degrees of HDP violations and their $b a$-construction-like constructions are either more prolific or more restricted. Investigations of these cross-linguistic word order facts may offer more insights into the characteristics of the SSH. Fourth, the view presented here crucially relies on the assumptions that languages differ in terms of HDPs. This view conflicts with Biberauer et al.'s (2014) treatment of the final-over-final constraint (FOFC), which crucially relies on the Antisymmetry Theory. If the present analysis is on the right track, the effects of FOFC might also be subject to an interface-based approach.

\section{Acknowledgments}

I thank Michael Yoshitaka Erlewine, Hun-tak Thomas Lee, Wei-wen Roger Liao, Tzong-hong Jonah Lin, Sze-wing Tang, Wei-tien Dylan Tsai, and three anonymous SCL reviewers for comments on earlier versions of this work, as well as the organizers and audiences at the Workshop on Word Order of Heads at The Chinese University of Hong Kong (October 2016) and at a colloquium at National Tsing Hua University (March 2017). Special thanks to Sze-wing Tang for inviting me to work on the topic of word order variations. All errors are my own.

\section{References}

Aldridge, Edith. 2012. PPs and applicatives in late Archaic Chinese. Studies in Chinese Linguistics 33(3). 139-164.

Alexiadou, Artemis. 2014. Active, middle, and passive: The morpho-syntax of voice. Catalan Journal of Linguistics 13. 19-40.

Baker, Mark. 2008. The macroparameter in a microparametric world. In Theresa Biberauer (ed.), The limits of syntactic variation, 351-374. Amsterdam: John Benjamins.

Benett, Paul A. 1981. The evolution of passive and disposal sentences. Journal of Chinese Linguistics 9(1). 61-90. 
Biberauer, Teresa, Anders Holmberg \& Ian Roberts. 2007. Disharmonic word-order systems and the final-over-final-constraint (FOFC). In Antonietta Bisetto \& Francesco E. Barbieri (eds.), Proceedings of the 33rd Incontro di Grammatica Generativa, 86-105. Bologna: Università di Bologna.

Biberauer, Theresa, Anders Holmberg \& Ian Roberts. 2014. A syntactic universal and its consequences. Linguistic Inquiry 45(2). 169-225.

Biberauer, Theresa \& Michelle Sheehan. 2012. Disharmony, antisymmetry, and the final-over-final constraint. In Myriam Uribe-Etxebarria \& Vidal Valmala (eds.), Ways of structure building, 206-244. Oxford: Oxford University Press.

Borer, Hagit. 1984. Parametric syntax. Dordrecht: Foris.

Chao, Yuen-ren. 1968. A grammar of spoken Chinese. Berkeley: University of California Press.

Cheng, Lisa L.-S. 2007. Verb copying in Mandarin Chinese. In Norbert Corver \& Jairo Nunes (eds.), The copy theory of movement, 151-174. Amsterdam: John Benjamins.

Chomsky, Noam. 1986. Knowledge of language: Its nature, origin, and use. New York: Praeger.

Chomsky, Noam. 1995. The minimalist program. Cambridge, MA: MIT Press.

Chomsky, Noam. 2000. Minimalist inquiries: The framework. In Roger Martin, David Michaels \& Juan Uriagereka (eds.), Step by step: Essays on minimalist syntax in honor of Howard Lasnik, 89-155. Cambridge, MA: MIT Press.

Chomsky, Noam. 2001. Derivation by phase. In Michael Kenstowicz (ed.), Ken Hale: A life in language, 1-52. Cambridge, MA: MIT Press.

Creissels, Denis. 2005. SVOX constituent order and constituent order alternations in West African languages. In Proceedings of the 31st Annual Meeting of the Berkeley Linguistic Society, 1-15, Berkeley.

Djamouri, Redouane, Waltraud Paul \& John Whitman. 2013. Syntactic change in Chinese and the argument-adjunct asymmetry. In Guangshun Cao, Hilary Chappell, Redouane Djamouri \& Thekla Wiebusch (eds.), Breaking down the barriers: Interdisciplinary studies in Chinese linguistics and beyond, vol. 2, 577-594. Taipei: Academia Sinica.

Epstein, Samuel David, Erich Groat, Ruriko Kawashima \& Hisatsugu Kitahara. 1998. A derivational approach to syntactic relations. New York: Oxford University Press.

Ernst, Thomas. 2002. The syntax of adjuncts. Cambridge: Cambridge University Press.

Feng, Shengli. 2000. Hanyu yunlü jufa xue [Prosodic syntax in Chinese]. Shanghai: Shanghai Jiaoyu Chubanshe [Shanghai education press].

Fox, Danny. 1995. Economy and scope. Natural Language Semantics 3(3). 283-341.

Fox, Danny. 2000. Economy and semantic interpretation. Cambridge, MA: MIT Press.

Fox, Danny \& David Pesetsky. 2005. Cyclic linearization of syntactic structure. Theoretical Linguistics 31. 1-45.

Geuder, Wilhelm. 2004. Depictives and transparent adverbs. In Jennifer R. Austin, Stefan Engelberg \& Gisa Rauh (eds.), Adverbials: The interplay between meaning, context, and syntactic structure, 131-166. Amsterdam: John Benjamins. 
Haig, Geoffrey. 2001. Linguistic diffusion in present-day East Anatolia: From top to bottom. In Alexandra Aikhenvald \& Robert Dixon (eds.), Areal diffusion and genetic inheritance: Problems in comparative linguistics, 192-224. Oxford: Oxford University Press.

Huang, C.-T. James. 1982. Logical relations in Chinese and the theory of grammar. Cambridge, MA: MIT dissertation.

Huang, C.-T. James. 1984. Phrase structure, lexical integrity, and Chinese compounds. Journal of Chinese Language Teachers Association 19. 53-78.

Huang, C.-T. James. 1992. Complex predicates in control. In Richard K. Larson, Sabine Iatridou, Utpal Lahiri \& James Higginbotham (eds.), Control and grammar, 109-147. Dordrecht: Kluwer.

Huang, C.-T. James. 1994. More on Chinese word order and parametric theory. In Barbara Lust, Margarita Suñer \& John Whitman (eds.), Syntactic theory and language acquisition: Crosslinguistic perspectives, vol. 1, Heads, projections, and learnability,15-35. Mahwah, NJ: Lawrence Erlbaum.

Huang, C.-T. James. 2006a. Resultatives and unaccusatives: A parametric view. Bulletin of the Chinese Linguistic Society of Japan 253. 1-43.

Huang, C.-T. James. 2006b. The macro-history of Chinese syntax and the theory of change. Paper presented at the Chinese Linguistics Workshop, University of Chicago.

Huang, C.-T. James. 2015. On syntactic analyticity and parametric theory. In Audrey Li, Andrew Simpson \& Wei-tien Dylan Tsai (eds.), Chinese syntax in a crosslinguistic perspective, 1-48. Oxford: Oxford University Press.

Huang, C.-T. James, Y.-H. Audrey Li \& Yafei Li. 2009. The syntax of Chinese. Cambridge: Cambridge University Press.

Huang, C.-T. James \& Ian Roberts. 2017. Principles and parameters of Universal Grammar. In Ian Roberts (ed.), Oxford handbook of universal grammar, 307 354. Oxford: Oxford University Press.

Jackendoff, Ray. 1972. Semantic interpretation in generative grammar. Cambridge, MA: MIT Press.

Kayne, Richard. 1994. The antisymmetry of syntax. Cambridge, MA: MIT Press.

Kayne, Richard. 2004. Antisymmetry and Japanese. In Lyle Jenkins (ed.), Variation and universals in biolinguistics, 3-37. Amsterdam: Elsevier.

Koopman, Hilda. 1984. The syntax of verbs. Dordrecht: Foris.

Koopman, Hilda. 1992. On the absence of case chains in Bambara. Natural Language and Linguistic Theory 10(4). 555-594.

Kratzer, Angelika. 1996. Serving the external argument from its verb. In Johan Rooryck \& Laurie Zaring (eds.), Phrase structure and the lexicon, 109-137. Dordrecht: Kluwer.

Kuo, Pei-jung. 2010. Transitivity and the ba construction. Taiwan Journal of Linguistics 8(1). 95-128.

Larson, Richard. 1988. On the double object construction. Linguistic Inquiry 19(3). 335-391.

Lee, Hui-chi. 2008. Obligatory object shift in Taiwanese Southern Min. In Shin-mei Kao \& Shelley Ching-yu Hsieh (eds.), NCKU FLLD Monograph series vol. 1: Languages across cultures, 151-170. Tainan: National Cheng Kung University. 
Li, Y.-H. Audrey. 1985. Abstract case in Chinese. Los Angeles, CA: USC dissertation.

Li, Y.-H. Audrey. 1987. Duration phrases: Distributions and interpretation. Journal of Chinese Language Teachers Association 22(3). 27-65.

Li, Y.-H. Audrey. 1990. Order and constituency in Mandarin Chinese. Dordrecht: Kluwer.

Li, Y.-H. Audrey. 2006. Chinese ba. In Martin Everaert \& Henk van Riemsdijk (eds.), The Blackwell companion to syntax, vol. I, 375-468. Oxford: Blackwell.

Liao, Wei-wen. 2017. Remarks on the final-over-final condition: A view from Chinese head-final structures. Studies in Chinese Linguistics 38(2). 93-118.

Lin, T.-H. Jonah. 2001. Light verb syntax and the theory of phrase structure. Irvine, CA: UC Irvine dissertation.

Lü, Shu-xiang. 1980. Xiandai hanyu babaici [Eight hundred words in Modern Mandarin]. Beijing: Shangwu yinshuguan [The commercial press].

Matsuoka, Mikinari. 2013. On the notion of subject for subject-oriented adverbs. Language 89(3). 586-618.

Matthews, Stephen \& Virginia Yip. 1994. Cantonese: A comprehensive grammar. Oxon: Routledge.

Mei, Tsu-lin. 1990. Tang, Song chuzhishi de laiyuan [The origin of the Tang and Song disposal construction]. Zhongguo Yuwen [Studies of the Chinese language] 216. 191-206.

Mulder, René \& Rint Sybesma. 1992. Chinese is a VO language. Natural Language and Linguistic Theory 10(3). 439-476.

Özsoy, A. Sumru. 2001. On 'small' clauses, other bare verbal complements and feature checking in Turkish. In Eser Erguvanlı Taylan (ed.), The verb in Turkish, 213-237. Amsterdam: Benjamins.

Paul, Waltraud. 2015. New perspectives on Chinese syntax. Berlin: De Gruyter Mouton.

Peyraube, Alain. 1996. Recent issues in Chinese historical syntax. In C.-T. James Huang \& Y.-H. Audrey Li (eds.), New horizons in Chinese linguistics, 161-214. Dordrecht: Kluwer.

Reinhart Tanya. 1997. Wh-in-situ in the framework of the Minimalist Program. Natural Language Semantics 6(1). 29-56.

Richards, Marc. 2004. Object shift and scrambling in North and West Germanic: A case study in symmetrical syntax. Cambridge: University of Cambridge dissertation.

Richards, Marc. 2007. Dynamic linearization and the shape of phases. Linguistic Analysis 33. 209-237.

Richards, Marc. 2008. Desymmetrization: Parametric variation at the PF-interface. Canadian Journal of Linguistics 53. 275-300.

Roberts, Ian. 2014. Syntactic change. In Andrew Carnie, Dan Siddiqi \& Yosuke Sato (eds.), The Routledge handbook of syntax, 391-408. Abingdon: Routledge.

Saito, Mamoru \& Naoki Fukui. 1998. Order in phrase structure and movement. Linguistic Inquiry 29(3). 439-474.

Sheehan, Michelle. 2013. Some implications of a copy theory of labeling. Syntax 16(4). 362-396. 
Sybesma, Rint. 1992. Causatives and accomplishments: The case of the Chinese ba. Leiden: Leiden University dissertation.

Sybesma, Rint. 1999. The Mandarin VP. Dordrecht: Kluwer Academic Publishers.

Tang, C.-C. Jane. 1990. Chinese phrase structure and the extended X'-theory. Ithaca, NY: Cornell University dissertation.

Tang, Sze-Wing. 2001. A complementation approach to Chinese passives and its consequences. Linguistics 39(2). 257-295.

Tang, Sze-Wing. 2015. Yueyu yufa jiangyi [Lectures on Cantonese grammar]. Hong Kong: The Commercial Press.

Teng, Shou-hsin. 1975. Predicate movements in Chinese. Journal of Chinese Linguistics 3(1). 60-75.

Travis, Lisa. 1984. Parameters and effects of word order variation. Cambridge, MA: MIT dissertation.

Vikner, Sten. 2006. Object shift. In Martin Everaert \& Henk van Riemsdijk (eds.), The Blackwell companion to syntax, vol. III, 392-436. Oxford: Blackwell.

Wei, Pei-chuan. 1993. Gu Hanyu jieci " $y u$ " de yanbian lüeshi [A brief history of the development of the preposition yu in Ancient Chinese]. Bulletin of the Institute of History and Philology Academia Sinica 62. 717-786.

Zhang, Cheng. 2002. Hanyu jieci cizu cixu de lishi yanbian [The historical evolution of the word order of prepositional phrases in Chinese]. Beijing: Beijing Yuyan Wenhua Daxue Chubanshe [Beijing Language and Culture University press].

Mailing address: Institute of Linguistics, Academia Sinica, No. 128, Academia Rd Sec. 2, Taipei 11529, Taiwan

Email: cshu@sinica.edu.tw

Received: December 13, 2016

Accepted: June 28, 2018 


\title{
句法-音韻介面中的參數保存：重訪把字句
}

\author{
舒志翔 \\ 中央研究院語言學研究所
}

\section{提要}

本文主張把字句為一種形狀保存所引發的移位結構。具體而言, 漢語的狀語多數出 現在動詞前, 以及一些雙賓句中強制性的 “把” 字移位現象, 皆從 “對稱句法假設” 下的可違反的 “中心語方向巨參數” 導出, 這個假設容許方向參數在整個句法衍生 過程中都能看見並制約語序。除了能夠解釋斯堪的納維亞語系中賓語移位的類似的 句法屬性，此分析也從古漢語以及班巴拉語的語序屬性得到額外的印證。

\section{關鍵詞}

把字句, 方向參數, 對稱句法假設, 非強制性移位, 句法-音韻介面 